Department of Econometrics and Business Statistics

http://business.monash.edu/econometrics-and-business-

statistics/research/publications

\title{
Investor-herding and risk-profiles: A State-Space model-based assessment
}

Harminder B. Nath and Robert D. Brooks

March 2020

Working Paper 09/20 


\title{
Investor-herding and risk-profiles: A State-Space model-based assessment
}

\author{
Harmindar B. Nath*, Robert D. Brooks \\ Department of Econometrics and Business Statistics, \\ Monash University, Caulfield East 3145, Australia
}

\section{Abstract}

This paper, using the Australian stock market data, examines the investor-herding and riskprofiles link that has implications for asset pricing, portfolio diversification and foreign investments. As investors may herd towards a specific factor, sector or style to combat market conditions for optimizing investment returns, examining such herding can reveal investors' risk profiles. We employ State-Space models for extracting time series of herd dynamics and the proportion of signal explained by herding (POSEH). Market volatility has a significant negative effect on PoSEH, with the most/least effect on high/low performance days of stock returns. Using quantile regression, we observe that herding and adverseherding can emerge during the worst and best performance days of stock returns, and that extreme volatility can bring herding to a near halt. The study reveals the presence of a regulated stock market environment and risk-aversion tendencies among investors.

JEL-classification: C31, C32, G12, G14

Key words: Herd behaviour, Risk aversion, State-Space models, Quantile regression.

\footnotetext{
*Corresponding author:

Tel: +61 39903 4345; Fax: +61 399032007

Email addresses: mindi.nath@monash.edu (H.B. Nath), Robert.brooks@monash.edu (R.D. Brooks)
} 


\section{Introduction}

Social psychology experiments on the behaviour of individuals in group situations reveal that individuals conform to group opinion, even when they do not agree with the group or believe that the group is wrong - a phenomenon known as herd behaviour (Asch, 1952). In stock markets situations investors may adapt to herd behaviour due to lack of confidence in their own judgement, or due to social coherence - 'others are doing, so they must do', or lured by successes of others and want to take advantage of opportunities availed by others or getting excited as a gambler to the thought of making quick easy money. Others may herd because they find it easier to dive into a risky venture in the company of others. Prechter (2001) asserts that 'it is a lesser-known fact that the vast majority of professionals herd just like the naïve majority'. Based on a survey, Shiller \& Pound (1989) find herding to be common among institutional investors as they place a significant weight on the advice of other professionals in making their buy and sell decisions in volatile markets.

The existence of herd behaviour in a market challenges the validity of the efficient market hypothesis $(\mathrm{EMH})^{1}$ that portrays that all investors are rational and possess the same full set of information for assessing the expected stock prices (Fama, 1970). The lack of full use of available information by market participants due to herding can intensify the inefficiency of the market leading to a disequilibrium relation between risk and return. Thus, herding can be viewed as a signal of an inefficient market, and an inefficient market may be interpreted as riskier than an efficient market. Discussing the economic implications of herding in the Taiwanese market, Demirer et al. (2010) point to its likely knock-on effect on portfolio management and the need to design policies like banning the short sales to deal with its negative effect on asset pricing.

Previous research (e.g., Chang, Cheng and Khorana (CCK), 2000; Demirer et al., 2010; Lao and Singh, 2011; Yao et al., 2014) indicates that emerging markets that lack regulation, transparency and information efficiency are prone to herd behaviour, and that developed markets show no evidence of herding (Christie and Huang, 1995; CCK, 2000; Henker et al., 2006). In these studies, US as the developed market and China, Taiwan and South Korea as

\footnotetext{
${ }^{1}$ See Lao and Singh (2011) and references therein for more details.
} 
the emerging markets are the most common markets being investigated. This paper focuses on the Australian market, a developed market in the Asia and Pacific region and the only developed market to survive a recession following the Global Financial Crisis (GFC) in 2008 (Davis, 2011). This makes the Australian stock market an interesting market for examining the investor-herding and risk-profiles link. Moreover, while most of the markets around the globe recovered and surpassed their pre-GFC stock market indices well before 2017, the Australian stock market in 2017 was still struggling to break the ceiling of its pre-GFC index that grew from 3133 in March 2000 to 6873 by October 2007. The few studies (Henker et al., 2006; Chiang and Zheng, 2010; Bohl et al., 2013) that have examined herding in the Australian market either use very small sample periods or a very small sample of stocks and present conflicting evidence. This is also the first study to combine the strengths of quantile regression and State Space modelling for understanding the investor herd behaviour.

While the concept of regular herd behaviour is easily understood and much explored via the use of the Christie and Huang (1995) and CCK (2000) models and their extensions (e.g., Chiang and Zheng, 2010; Chaing, Li and Tan, 2010; Lao and Singh, 2011; Yao, Ma and He, 2014), the concept of adverse herding is relatively unexplored in the stock market settings. Effinger and Polborn (2001) explain the presence of adverse herding phenomenon via a model of competing agents facing incentives where doing things differently to the mob establishes smartness. Huang and Salmon (2004) discuss the concept of adverse herding in the context of stock markets. They argue that adverse herd behaviour is likely to emerge due to a high level of uncertainty and divergence of opinion among market participants with no clear indication of the future direction of the market. It makes a defensive stock beta (beta $<1$ ) appear more defensive and an aggressive stock beta (beta $>1$ ) more aggressive, inflating the cross-sectional dispersion of betas.

This paper examines the investor herding and risk-profiles link using data that covers the pre-, post-, and the GFC periods, and also the short-sales ban period. We employ the Hwang and Salmon (2004) model for examining herding as well as adverse herding behaviour. Our benchmark results are based on applying the ordinary least squares (OLS) method for estimating betas as in Hwang and Salmon (2004) but employ quantile regression for capturing the heterogeneous responses of stock returns to market movements and 
other factors. This eliminates the need for using subjective judgement in defining the extreme market conditions while evaluating the changing relationship between the stock returns and market returns, and/ or other factors in response to the perceived risk and profit opportunities during periods of extreme market expansions and contractions. If investors' investment strategies change due to market conditions and other factors, it would be reflected in the quantile regression estimates of betas at the extreme quantiles and would be different from the OLS based estimates. If different, it would mean that the stocks' risk exposure to market conditions and other factors are not homogenous and that investors price their assets differently in response to the market risk situations. Thus, the time series dynamics of herding extracted using the State Space models from such varied factor sensitivities and viewed along with the market conditions would reveal investors' risk tendencies. Many studies (e.g., Lakoniskok et al., 1992, Grinblatt et al., 1995) report that herding is stronger among small size stocks; our study focuses only on large size stocks. It also does not segregate institutional investors from the individual investors.

As investors may herd towards a specific factor, sector or style to combat market conditions and to optimize their investment returns, we investigate herding towards the market portfolio as well as_herding towards book-to-market (BM) ratio ${ }^{2,3}$ and trading volume (TR) factors. Since over and under valuations of stocks as reflected in the BM ratios are indicators of investors' risk aversion tendencies (Arnott et al., 2005), viewing the level of herding towards BM factor together with the prevalence of the market conditions would reflect investors' risk tendency at a given point in time. There is much evidence that trading volume sustains stock price movements. Stickel and Verrecchia (1994) assert that “a conventional wisdom on Wall Street is that volume is the fuel for stock prices". Low trading volume is likely to reverse price changes more than the high trading volume. As herding can lead to significant mispricing, it would be of interest to examine herding towards the trading volume to find out what information on investor risk profile is conveyed by such herding. Our study of herding towards the BM and TR factors is different from the previous studies

\footnotetext{
2 Viewing the algebraic development of the BM ratio, Peterkort and Nielsen (2005) explain that the BM ratio is the product of 'financial risk' (debt divided by market equity) and 'asset risk' (the inverse of debt divided by book equity).

${ }^{3}$ In seeking to assign the BM ratio a 'risk-based' or a 'mispricing' connotation, Dempsey (2010) using Australian data concludes that 'BM effect cannot be divorced from underlying leverage as a risk factor'. He adds, 'the BM variable absorbs market movements as a proxy for financial risk and is seen as the price adjustment mechanism of convergence to norm from more extreme values whatever triggers such movement'.
} 
that explore the existence of herding towards the market portfolio by controlling the effect of volume via dummy variables, or by forming quintile portfolios on BM ratios.

We observe herding levels vary across the quantiles of the return distribution. The existence of herding and adverse herding at the extreme quantiles suggests that such behaviour can emerge during the worst and the best performance days of stock returns. The proportion of signal explained by herding (POSEH) based on the cross-sectional standard deviations of average and extreme quantiles' betas of the return distribution is not the same; investors seem to value their assets differently on the low and the high-performance days of stock returns compared to an average day. Like Hwang and Salmon (2004), our findings do not support the common belief reflected in past studies (e.g., Demirer et al., 2010; Chiang and Zheng, 2010; Yao et al., 2014) via the Christie and Huang (1995) and CCK (2000) methodologies that herding occurs during market stress. We find that market volatility has a significant negative influence in reducing PoSEH; it has the most (least) effect on high (low) performance days of the stock returns. While herding towards trading volume is stronger during the low performance days of stock returns, its movement towards the market portfolio and BM factors is stronger during the high-performance days. As the size of the signal explained by the BM factor herding is consistently high across all levels of the return distribution and experiences minimal effect of market volatility, it can be inferred that for risk-minimising investors herd towards BM frequently, a risk leverage factor. Moreover, since herding (adverse herding) takes place during calmer (turbulent) periods when the investor confidence is high (low) in the market performance, it not only suggests a link between the investor herding and their risk-profiles but also endorses risk-aversion among investors. Absence of herding during the short-selling ban period (Nov 2008 - May 2009) suggests the effectiveness of the regulatory system.

The structure of the paper is as follows. Section 2 outlines some literature on herding and the scope of the problem. Section 3 details the data and the sampling design. While Section 4 provides the methodology, Section 5 presents results and their discussion. Section 6 concludes the paper. 


\section{Related empirical studies on herding}

The literature on empirical studies of herd behaviour documents extensive use of the return dispersion-based models of Christie and Huang (1995) and CCK (2000) and their extensions (e.g., Chiang et al., 2010; Lao \& Singh, 2011; Bohl et al., 2013; Yao et al., 2014). These models are basically cross sectional in nature and are based on the notion that herding is likely to occur during extreme market stress. The methodologies explore the idiosyncratic risk behaviour of stock returns during different market conditions (Demirer et al.,_2010), and as such there is no direct comparison between results from this strand of models and the Hwang and Salmon (2004) models applying dispersions in the systematic risk. Although, the Hwang and Salmon (2004) method also uses the cross-sectional relationships, it includes a time dimension to the methodology that allows tracking finer evolutionary movements in herd behaviour. This section briefly outlines research that relates to and sets up background for the current study.

Hwang and Salmon (2004) argue that as the Christie and Huang (1995) methodology does not control for movements in fundamentals; it is not possible to separate investor moves being due to adjustments based on fundamentals or to herding, and therefore, whether the market is moving towards a relatively efficient or an inefficient outcome. They build their model upon the CAPM betas - the systematic risk measure of equities, which as per the literature (e.g., Fama and MacBeth, 1973; Ferson and Harvey, 1991, 1993) change over time. They argue that a time-variation effect in CAPM betas is unlikely due to fundamental shifts as capital restructuring events of firms are infrequent and are not likely to occur over short time horizons. Thus, the empirical evidence of the time effect in these betas is more likely to emerge out of behavioural anomalies like investor sentiment or herding. The method allows measuring herd movements, which may follow a different path from the market itself, separating them from asset returns movements caused by shifts in fundamentals, and thus encapsulating investors' herding as well as adverse herding tendencies. The application of their method to the US and the South Korean stock markets reveals the presence of herding towards the market portfolio during up as well as down market conditions. Contrary to the common belief put forward by earlier researchers, they observe investors exhibiting herd behaviour during calmer periods of the market and reduce 
their herding activity or move away from it during periods of crisis. It reappears in quieter times when investors are confident of the direction of the market.

Based on the Christie and Huang (1995) and CCK (2000) models and a partial use of the Hwang and Salmon (2004) model in the Taiwanese stock market, Demirer et al. (2010) report strong evidence of herding in all sectors and that the herding effect is more noticeable during periods of market downturns. However, this study does not provide information on the proportion of signal explained by herding or the presence of adverse herding. It is not clear if the inclusion of control variables such as market volatility and market returns enhance or reduce the degree of herding. A significant negative coefficient on market volatility simply suggests reduction in the cross-sectional dispersion of betas due to increase in market volatility, and as such there is no direct comparison between the outcomes of their study derived from the Christie and Huang (1995), CCK (2000) and Huang and Salmon (2004) methodologies. Therefore, the conclusion that "herding is more likely to occur during periods of market stress, i.e., highly volatile periods" is not supported.

Applying the Christie and Huang (1995) and CCK (2000) models of herding, Henker et al. (2006) investigate intraday investor herding behaviour in the Australian Stock market for the period 2001 - 2002 and find no evidence of herding. Chiang and Zheng (2010) use a modified version of the CCK (2000) model to study herding in the industrial sector stocks in 18 international markets including Australia for the period May 1988 - April 2009. For Australia, their study (Tables 2 and 3 ) exhibits the market index herding in the absence as well as in the presence of US market variables, and displays such herding (c.f., Table 5, Panel A4) during the Global Financial Crisis (GFC) period in the presence of US market variables. A positive and significant coefficient of CSADUs, $t$ in this study simply implies a co-varying risk associated with industry sectors; a shock in a similar industry sector in US tends to get transmitted to Australia. However, their Table 4, Panel A, does not show such herding in rising or declining market conditions in the presence of US market variables ${ }^{4}$.

\footnotetext{
${ }^{4}$ Using 23 countries and forming 4 regions (North America, Europe, Japan and Asia), Fama \& French (2012) test whether asset prices are integrated across markets, but do not find strong support for such integration.
} 
Using the CCK (2000) model, Bohl et al. (2013) examine the effect of short-selling bans imposed following the GFC on institutional investors' herding behaviour in six stock markets (US, UK, Germany, France, South Korea and Australia). They observe Australia ${ }^{5}$ to be the only market to show a weak tendency (results significant at the $10 \%$ level) for herding. Bohl et al. (2013) document many studies that point to overvaluation of stock prices from shortselling restrictions. However, Bai et al. (2006) show that if investors are risk averse, shortselling bans may cause over or under valuations of stock prices depending on the degree of asymmetric information in a given stock. Bohl et al. (2013) explain that "restricting shortsellers causes uncertainty about stock prices, which may reduce investor's trust in the market consensus resulting in adverse herding". Thus, while the over and under valuations of stocks as reflected in the BM ratios (Arnott et al., 2005) are indicators of investor risk aversion tendencies, the presence of adverse herding in a market is also a sign of risk aversion as investors resort to fundamentals.

We follow the Huang and Salmon (2004) methodology of herding as it allows one to identify periods of herding, adverse herding or neither of the two, and the turning points in these movements. Such tendencies cannot be observed with the Christie and Huang (1995) and CCK (2000) models. The use of the Hwang and Salmon linear factor model provides additional insights into other dimensions towards which the investors may herd in addition to the market factor. It facilitates examining herding during calmer, crisis and short-selling ban periods, and thus helps infer behavioural implications of such herding in stock markets. If investors are risk averse, they are likely to stick to fundamentals during the major downturns of the market and an adverse herd behaviour should emerge.

\section{Data Description}

Our sample consists of all constituent stocks in the S\&P/ASX200 for the period $1^{\text {st }}$ October 2000 to $31^{\text {st }}$ May 2017. The S\&P/ASX200 index represents approximately 89 percent of the total market capitalisation in the Australian market. It is most widely used as 'today's portfolio benchmark index'. The S\&P/ASX200 was established in April 2000, but seemed to

\footnotetext{
${ }^{5}$ A study based on 44 stocks comprising all financial stocks on the ASX200 and five other stocks that were part of the Australian Prudential Regulation Authority-regulated business. The naked short-sale ban on all stocks was imposed between 22 Sep 2008 and $18^{\text {th }}$ Nov 2008, and the short-sale ban for the period $19^{\text {th }}$ November 2008 and $24^{\text {th }}$ May 2009.
} 
have teething problems at the start, so we start our sample from October 2000 . The constituents of the index are reviewed every quarter by the regulatory authority making some stocks leave and new ones enter the index. However, in our sampling design we use 200 stocks in a year that were part of the ASX200 on $31^{\text {st }}$ December of the previous year; the only exception is the start period where 200 stocks from the September quarter of year 2000 are included in our sample. Daily end of the day stock prices, market capitalization, trading volume, market-to-book values, as well as the S\&P/ASX200 index values are downloaded from DataStream. We use the 30-day Cash rate as set by Reserve Bank of Australia Board at monthly meetings as a proxy for the daily risk-free rate of return and is also downloaded from DataStream. Excluding the non-trading days due to weekends and public holidays, our sample ends with 4216 daily observations on each variable for each stock covering a period of 200 months and approximately 200 stocks in each month. Initially, we used the Hwang and Salmon (2004) sampling design for selecting our sample, but our sample lost too many stocks as we followed them back in time. The number of stocks per month over 17 years' period varied from 200 in 2017 to 106 in 2000. This sampling design would have exposed our findings to survivorship and sample selection bias discussed in Hwang and Salmon (2004). Moreover, we could not be sure of the robustness of our findings based on sample comprising vast variation in its size. Nevertheless, the pattern of herding was observed to be similar based on Hwang and Salmon (2004) and our current sample design.

\section{Research design and Modelling Framework}

We follow the Hwang and Salmon (2004) methodology and set up models within the following framework. The Capital Asset Pricing Model (CAPM) in equilibrium links the expected excess returns on a risky security $i$ and the contemporaneous expected excess returns on a market portfolio in period $t$ as

$$
E_{t}\left(r_{i t}\right)=\beta_{\text {imt }} E_{t}\left(r_{m t}\right), \quad i=1,2, \quad, N
$$

where $r_{i t}$ and $r_{m t}$ are the excess returns on security $i$ and the market portfolio at time $t$, respectively, $\beta_{i m t}$ is the systematic risk parameter, and $E_{t}(\cdot)$ represents the conditional expectation at time $t$. The systematic risk varies over time. The existence of herding is likely 
to bias relationship (1) and affect $E_{t}\left(r_{i t}\right)$ and $\beta_{i m t}$. Let $\beta_{i m t}^{b}$ denote the biased systematic risk parameter. Hwang and Salmon (2004) introduce herding towards the market portfolio parameter $h_{m t}$ at time $t$ as

$$
\beta_{i m t}^{b}=\beta_{i m t}-h_{m t}\left(\beta_{i m t}-1\right)
$$

Relation (2) implies that when $h_{m t}=0$, there is no herding towards the market and the equilibrium CAPM applies; when $h_{m t}=1$, there is perfect herding towards the market portfolio, making $\beta_{i m t}^{b}=1$, and, therefore, $0<h_{m t}<1$ indicates some degree of herding depending on the magnitude of $h_{m t}$. The Hwang and Salmon (2004) measure of herding at time $t$ is based on the cross-sectional standard deviations (CSSD) of $\beta_{i m t}^{b}$ and $\beta_{i m t}$, and is defined by relation

$$
\operatorname{CSSD}\left(\beta_{i m t}^{b}\right)=\operatorname{CSSD}\left(\beta_{i m t}\right)\left(1-h_{m t}\right)
$$

As $\operatorname{CSSD}\left(\beta_{\text {imt }}\right)$ and $h_{m t}$ are both non-observable, Hwang and Salmon suggest building a State-Space model and use a Kalman filter for estimating $h_{m t}$. Taking natural logarithm of relation (3) and allowing $\operatorname{CSSD}\left(\beta_{\text {imt }}\right)$ to be stochastic, one can express the relation as

$$
\log \left[\operatorname{CSSD}\left(\beta_{i m t}^{b}\right)\right]=\mu_{m}+v_{m t}+H_{m t}
$$

where $\mu_{m}=E\left[\log \left[\operatorname{CSSD}\left(\beta_{i m t}\right)\right]\right], v_{m t} \sim i i d\left(0, \sigma_{m v}^{2}\right), H_{m t}=\log \left(1-h_{m t}\right)$.

Now assuming $H_{m t}$ follows a dynamic AR(1) process with mean zero, we can express $H_{m t}$ as

$$
H_{m t}=\phi_{m} H_{m t-1}+\eta_{m t}
$$

where $\eta_{m t} \sim \operatorname{iid}\left(0, \sigma_{m \eta}^{2}\right)$.

Equations (4) and (5) represent a standard State-Space model, which can be estimated using a Kalman filter, with Eq (4) being the measurement equation and Eq (5) the state equation. The primary interest here is on the dynamic movements in the state variable $H_{m t}$ captured by Eq (5). When $\sigma_{m \eta}^{2}$ is zero, $H_{m t}$, and therefore, $h_{m t}$ is also zero for all $t$. Thus, a significant value of $\sigma_{m \eta}^{2}$ would imply the existence of herding and a significant $\phi$ value would support the autoregressive structure assumed in this model. For herding process $H_{m t}$ to be stationary, $|\phi| \leq 1$. However, in an empirical study a sample estimate of $\beta_{i m t}^{b}$ will be required which will involve a sampling error and will affect the $\operatorname{CSSD}\left(\beta_{\text {imt }}^{b}\right)$. We let $b_{\text {imt }}$ 
denote a sample estimate of $\beta_{i m t}^{b}$ and $\delta_{i m t}$ the sampling error in using this estimate, which is assumed to have mean and variance as $\left(0, \sigma_{m \delta}^{2}\right)$. Using $b_{i m t}$ as a sample estimate of $\beta_{i m t}^{b}$, the state space model in equations (4) and (5) can be re-specified as

$$
\begin{aligned}
& \log \left[\operatorname{CSSD}\left(b_{i m t}\right)\right]=\mu_{m}^{s}+H_{m t}+v_{m t}^{s} \\
& H_{m t}=\phi_{m} H_{m t-1}+\eta_{m t}
\end{aligned}
$$

In Eq (6), $\mu_{m}^{s}=E\left[\log \left[\operatorname{CSSD}\left(\beta_{\text {imt }}\right)\right]\right]+\mu_{\delta}$, where $\mu_{\delta}$ is an unknown mean factor due to sampling error, and $v_{m t}^{s} \sim \operatorname{iid}\left(0, \sigma_{m v}^{2}+\sigma_{m \delta}^{2}\right)$. Clearly, $\mu_{m}^{s} \neq \mu_{m}$ and $\operatorname{Variance}\left(v_{m t}^{s}\right)>$ $\operatorname{Variance}\left(v_{m t}\right)$, and the true mean $\mu_{m}$ cannot be identified, but the herding state variable $H_{m t}$ in equations (6) and (7) is not impacted by the estimation error. However, due to sampling error it would be harder for estimates of $\phi$ to be significant. The estimation error impact could be minimised using a longer estimation time interval to compute beta estimates, but it would make it difficult to track rapid changes in herding. It is documented in the literature (e.g., Henker et al. 2006) that herding does not show up in very small estimation time intervals as well as in larger than one-month time frame.

Hwang and Salmon (2004) test the robustness of their herding measure by comparing its performance in models that employ CSSD of betas estimated from the market and the Fama and French (1993) three factor (FF-3) models. They extract herding movements towards the market portfolio from the CSSD of betas obtained from these models in the absence and presence of market volatility, market returns, SMB (Small minus Big), HML (High minus Low) and some microeconomic variables as controls. It follows that the performance of herding variable $H_{m}$ is comparable, with POSEH approximately $40 \%$ in each model (Table 3, Panel A). While market volatility and market returns play important roles in these models, SMB, HML and microeconomic factors have no effect. Based on FF-3 betas, herding towards SMB (Table 3, Panel B) is not very persistent or smooth, and herding towards HML (Table 3, Panel C) is not explained well with PoSEH about 22\%. It seems that the use of FF-3 betas on SMB and HML are not able to capture the finer influence of size and BM factors. In relation to using CAPM or the FF-3 model for risk adjustment, Duan et al. (2019) remark that size and value factors in FF-3 model may also be exposed to other mispricing factors. As our sample consists of large stocks only and the interest is to capture 
the risk adjustment effect of BM factor, we do not use FF-3 model for measuring herding movements towards the BM factor.

We use models $(A)$ and $(B)$ defined below for computing sample estimates of biased betas for each security using daily data. For each month $t$, we fit the model

$$
r_{i d}=\alpha_{i t}^{b}+\beta_{i m t}^{b} r_{m d}+\varepsilon_{i d}, \quad i=1,2, \cdots, N ; d=1,2, \cdots, D
$$

for estimating monthly betas. In Eq (A), $r_{i d}$ is the excess returns on stock $i, r_{m d}$ the excess returns on the market portfolio on day $d, \alpha_{i t}^{b}$ is the intercept term that changes over time, and $\varepsilon_{i d}$ the $i i d\left(0, \sigma_{\varepsilon}^{2}\right)$ error term. Index $N$ represents the number of securities trading in month $t$ and $D$ the number of trading days for security $i$ in month $t$. To ensure the stability of the beta estimates a security must trade for at least 15 days in a month for inclusion in the sample. Eq (A) model is estimated using the OLS and the quantile regression methods, and for each month the CSSD of betas are calculated. Many herding studies document the presence of asymmetric herding effects under positive and negative market conditions. If the distribution of CSSD of betas is not symmetric the OLS based estimates of betas that capture the factor sensitivities at the average level may not serve well. Also, it is well known that the performance of the tests based on the OLS estimators that assume the errors to follow a normal distribution is compromised in the absence of normality. On the other hand, the quantile regression estimators are robust under such conditions and are not sensitive to the presence of extreme values in the response variable. Thus, we expect the use of quantile regression ${ }^{6}$ to provide an additional dimension in understanding the herding pattern resulting from the likely perceived risk during periods of extreme market conditions.

Next, the movements in herd behaviour are extracted from the time series of CSSD of betas via the State Space (SS) Models (A1) and (A2), defined as

$$
\log \left[\operatorname{CSSD}\left(b_{\text {imt }}\right)\right]=\mu_{m}^{s}+H_{m t}+v_{m t}^{s}
$$

\footnotetext{
${ }^{6}$ The use of quantile regression is not new in empirical economics, finance and many other business areas (see e.g., Buchinsky, 1997, 1998; Barnes \& Hughes, 2002; Engle \& Manganelli, 2004; Nath and Brooks, 2015). Barnes and Hughs (2002) employ quantile regression for studying the contribution of the one-factor capital asset pricing model beta risk in explaining returns. Nath and Brooks (2015) use quantile regression to show that the shape of the return distribution conditioned on the same level of exposure to idiosyncratic volatility risk, a residual risk after the systematic risk has been filtered, changes with the quantiles of the return distribution, suggesting that investors' investment strategies change with the level of exposure to risk and stakes involved.
} 


$$
\begin{aligned}
& H_{m t}=\phi_{m} H_{m t-1}+\eta_{m t} \\
& \log \left[\operatorname{CSSD}\left(b_{i m t}\right)\right]=\mu_{m}^{s}+H_{m t}+c_{m 1} \log \hat{\sigma}_{m t}+c_{m 2} r_{m t}+v_{m t}^{s} \\
& H_{m t}=\phi_{m} H_{m t-1}+\eta_{m t}
\end{aligned}
$$

where, $v_{m t}^{S}$ and $\eta_{m t}$ are error terms and are assumed to have the same structure as in Eq (6) and Eq (7). In Model (A2), the additional variables $\log \hat{\sigma}_{m t}$ and $r_{m t}$ represent the log of monthly market volatility and the monthly excess market returns, respectively, and $c_{m 1}$ and $c_{m 2}$ are their corresponding coefficients. While both Models (A1) and (A2) extract the herding factor from $\log \left[\operatorname{CSSD}\left(b_{\text {imt }}\right)\right]$, Model (A2) captures herd behaviour when the effects of $\log \hat{\sigma}_{m t}$ and $r_{m t}$ are controlled for. If the herding coefficient remains significant in the presence of variables $\log \hat{\sigma}_{m t}$ and $r_{m t}$, which reflect the state of the market, it would establish the robustness of the herd behaviour. Otherwise, the changes in $\log \left[\operatorname{CSSD}\left(b_{\text {imt }}\right)\right]$ could be due to factors other than herding.

The second model we adapt is the linear factor model discussed in Hwang and Salmon (2004). This model allows us to study herding towards the book-to-market and trading volume factors, identified as indicators of risk in Section 1, along with herding towards the market portfolio. Variable trading volume employed in this study is measured by turnover as

$$
\left[\text { Turnover }=\frac{\text { Trading volume } \times \text { Stock price }}{\text { Market capitalization }}\right] .
$$

Specifically, the linear factor model considered is

$$
\begin{gathered}
r_{i d}=\alpha_{i t}^{b}+\beta_{i m t}^{b} r_{m d}+\beta_{i B M t}^{b} B M_{i d}+\beta_{i T R t}^{b} T R_{i d}+\varepsilon_{i d} \\
i=1,2, \cdots, N ; d=1,2, \cdots, D
\end{gathered}
$$

In Eq. (B), BM stands for Book-to-Market, TR for Trading volume, and coefficients $\beta_{i B M t}^{b}$ and $\beta_{i T R t}^{b}$ are the corresponding factor sensitivity parameters that may have been affected by herding at time $t$. The intercept $\alpha_{i t}^{b}$ changes over time, and $\varepsilon_{i d}$ is the $i i d\left(0, \sigma_{\varepsilon}^{2}\right)$ error term. The other terms are as explained earlier. Estimates of $\beta_{i m t}^{b}, \beta_{i B M t}^{b}$ and $\beta_{i T R t}^{b}$ are obtained using daily data first before fitting the SS models for extracting the herd behaviour towards 
the market portfolio, BM and TR factors. In the following equations, we use $b_{i m t}, b_{i B M t}$ and $b_{i T R t}$ to denote the sample estimates of $\beta_{i m t}^{b}, \beta_{i B M t}^{b}$ and $\beta_{i T R t}^{b}$, respectively.

Model (B) is fitted using the OLS and the quantile regression estimation methods, and the herd behaviour is extracted by fitting the following SS models.

$$
\begin{aligned}
& \log \left[\operatorname{CSS} D\left(b_{i m t}\right)\right]=\mu_{m}^{s}+H_{m t}+v_{m t}^{S} \\
& H_{m t}=\phi_{m} H_{m t-1}+\eta_{m t} \\
& \log \left[\operatorname{CSS}\left(b_{i m t}\right)\right]=\mu_{m}^{S}+H_{m t}+c_{m 1} \log \hat{\sigma}_{m t}+c_{m 2} r_{m t}+v_{m t}^{s} \\
& H_{m t}=\phi_{m} H_{m t-1}+\eta_{m t} \\
& \log \left[C S S D\left(b_{i B M t}\right)\right]=\mu_{B M}^{s}+H_{B M t}+v_{B M t}^{S} \\
& H_{B M t}=\phi_{B M} H_{B M t-1}+\eta_{B M t} \\
& \log \left[C S S D\left(b_{i B M t}\right)\right]=\mu_{B M}^{S}+H_{B M t}+c_{m 1} \log \hat{\sigma}_{m t}+c_{m 2} r_{m t}+v_{B M t}^{S} \\
& H_{B M t}=\phi_{B M} H_{B M t-1}+\eta_{B M t} \\
& \log \left[C S S D\left(b_{i T R t}\right)\right]=\mu_{T R}^{S}+H_{T R t}+v_{T R t}^{S} \\
& H_{T R t}=\phi_{T R} H_{T R t-1}+\eta_{T R t} \\
& \log \left[C S S D\left(b_{i T R t}\right)\right]=\mu_{T R}^{S}+H_{T R t}+c_{m 1} \log \hat{\sigma}_{m t}+c_{m 2} r_{m t}+v_{T R t}^{S} \\
& H_{T R t}=\phi_{T R} H_{T R t-1}+\eta_{T R t}
\end{aligned}
$$

\section{Empirical results and discussion}

\subsection{Herding towards the market portfolio: Models (A1) and (A2)}

This section compares herding towards the market portfolio extracted from State Space Models (A1) and (A2) that employ CSSD of betas estimated using the OLS and the quantile regression methods from the market model. Results from this section provide a baseline for comparing herding movements towards the market portfolio and other factors extracted from the linear factor model in later sections. We start by describing properties of the cross- 
sectional standard deviations of the betas and the explanatory variables used in fitting SS Models (A1) and (A2).

\subsubsection{Characteristics of Market Excess Returns, Market volatility and Cross-Sectional} Standard Deviations of betas

Figure 1 displays time graph of monthly excess returns on the ASX200 index, and Columns 2 and 3 in Table 1, Panel A, report summary statistics of daily and monthly excess returns on the ASX200 index for the period $1^{\text {st }}$ October 2000 to $31^{\text {st }}$ May 2017. The daily excess returns for the index range between $-8.7 \%$ and $5.6 \%$, while the monthly excess returns vary between $-13.9 \%$ and $6.9 \%$. The daily and monthly mean excess returns are very close to zero, but there is considerable variation in them and both distributions are negatively skewed and leptokurtic, implying more positive returns than negative. The Jarque-Bera statistic for normality shows that daily as well as the monthly excess returns on the market index are non-Gaussian. The monthly excess returns dip sharply between August 2007 and September 2009, surrounding the GFC and the short-selling ban periods.

Figure 2 graphs monthly volatility in the ASX200 series. The volatility peaks during the GFC period of mid-2007 to 2008. Column 4 in Table 1, Panel A, reports properties of monthly volatility in the ASX200 series for the sample period. The volatility series is positively skewed and leptokurtic, suggesting that extreme volatility is less common. This series is non-Gaussian.

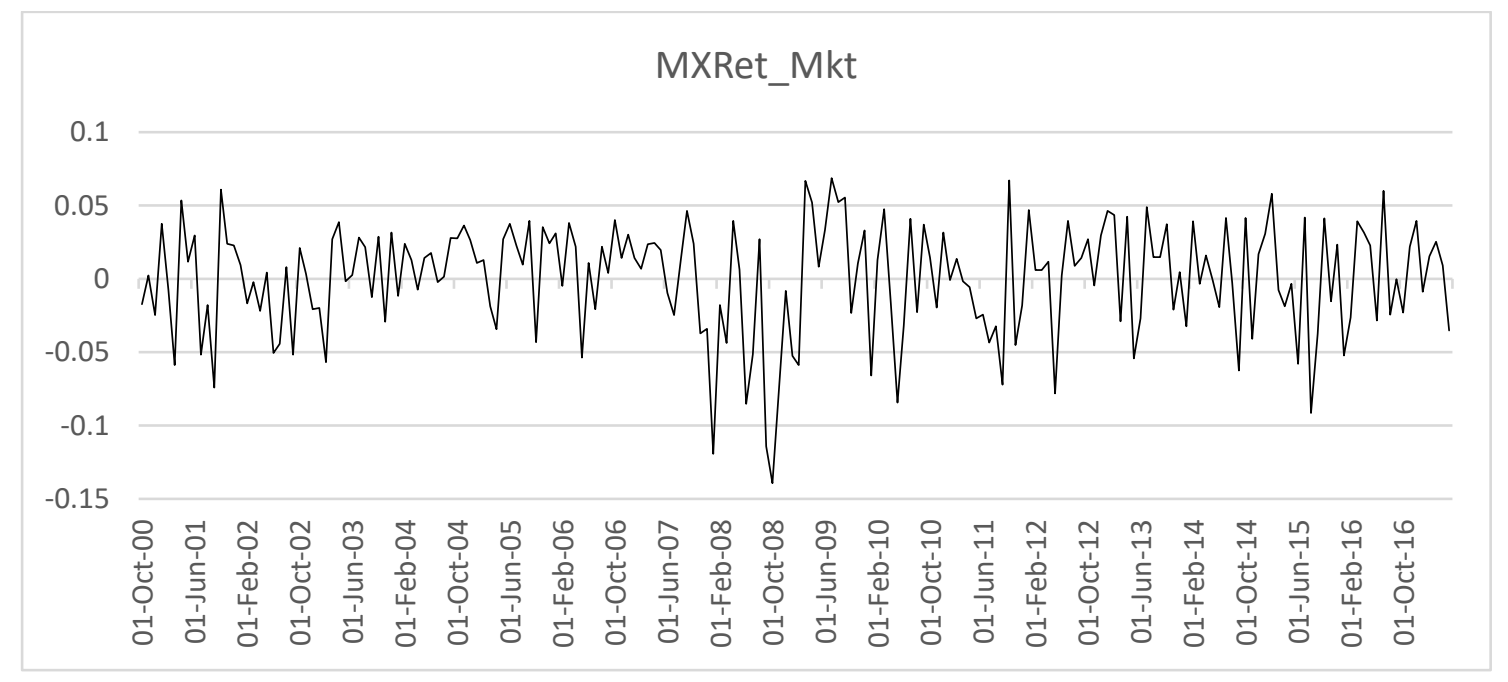

Fig. 1. Time Series of Monthly Excess returns on ASX200 Index (variable MXRet_Mkt). 


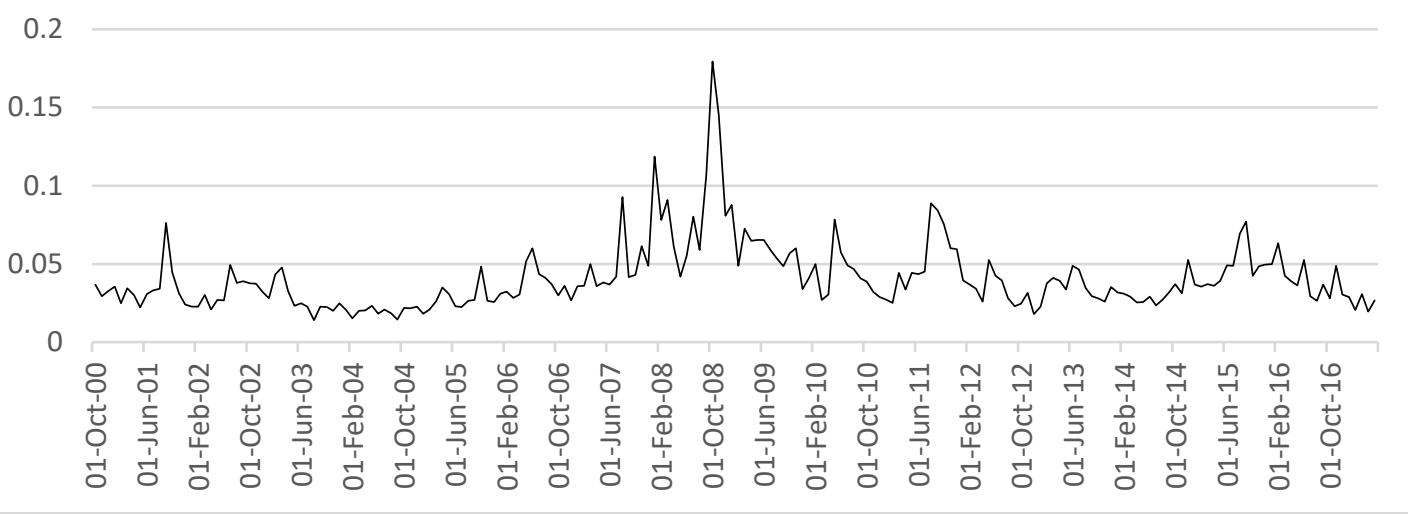

Fig. 2. Time Series of Volatility in Monthly ASX200 returns Index (variable MMktVol).

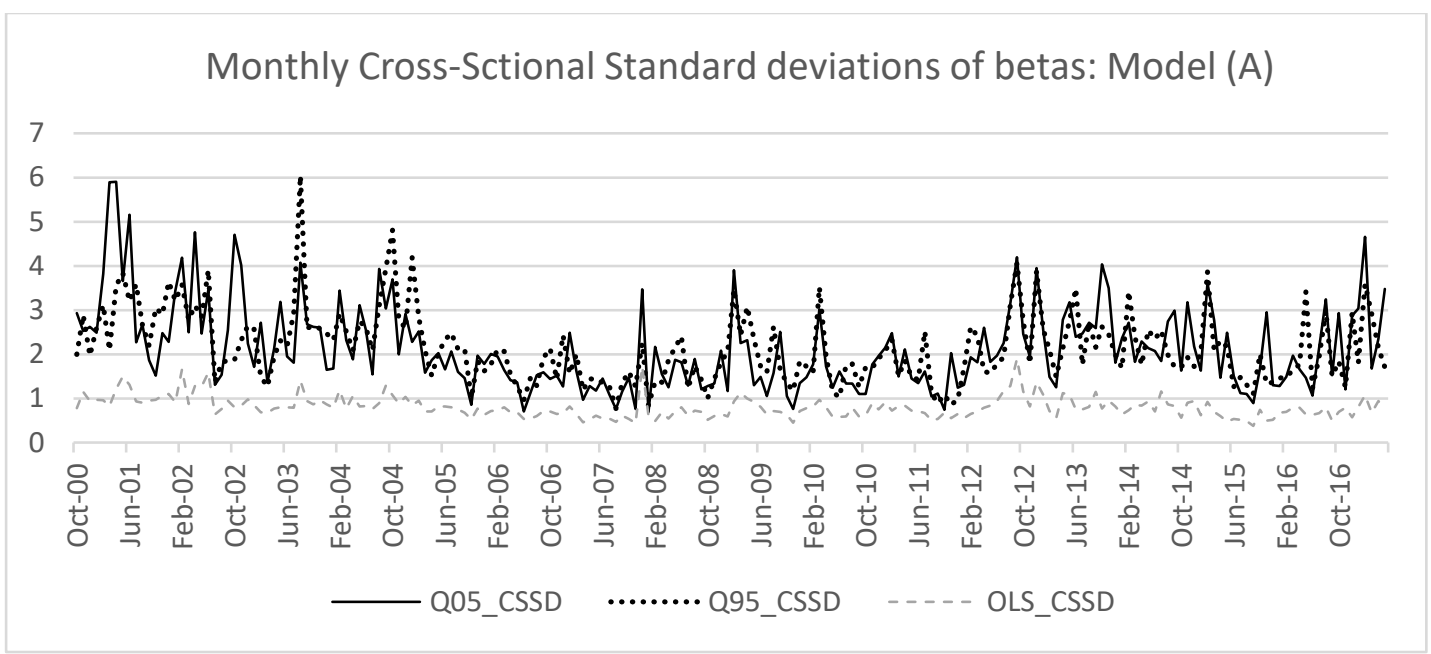

Fig. 3. Monthly Cross-Sectional Standard Deviations (CSSD) of betas based on Model (A). This figure graphs the CSSDs of betas obtained from fitting Model (A) via the Ordinary Least Squares (OLS) and the quantile regression estimation methods; Q05_CSSD and Q95_CSSD represent series at the $5^{\text {th }}$ and $95^{\text {th }}$ quantiles.

Table 1, Panel B, contains summary statistics of $\operatorname{CSSD}\left(b_{\text {imt }}\right)$ on ASX200 returns estimated using the OLS and the quantile regression methods, and the log (natural logarithm) of these CSSDs, the log-CSSD $\left(b_{i m t}\right)$. While all $\operatorname{CSSD}\left(b_{i m t}\right)$ series are non-Gaussian and positively skewed, their logged values are Gaussian. As the means and standard deviations of $\operatorname{CSSD}\left(b_{i m t}\right)$ and $\log -\operatorname{CSSD}\left(b_{i m t}\right)$ series at the extreme quantiles are much larger than the values based on the OLS method, we expect to find variation in herding patterns emerging from these series. Figure 3 displays monthly $\operatorname{CSSD}\left(b_{i m t}\right)$ estimated from Model (A) and employed in fitting Models (A1) and (A2), and Table 2 shows estimation output for Models (A1) and (A2). Figure 3 shows very little variation in OLS based CSSD $\left(b_{\text {imt }}\right)$ series compared to the ones based on the $5^{\text {th }}$ and $95^{\text {th }}$ quantiles. It suggests more uncertainty 
among betas from the extreme tail regions of the return distribution, and that excess market returns affect extreme returns differently to the returns on the average level.

Table 1

Summary statistics of Market Returns, Market Volatility and Cross-sectional Standard Deviations of betas.

Panel A: Summary statistics for Daily and Monthly Excess returns on ASX200 and monthly Volatility in ASX200 for the period Oct 2000 to May 2017 (4216 daily observations).

\begin{tabular}{|c|c|c|c|}
\hline & $\begin{array}{l}\text { Daily } \\
\text { Excess } \\
\text { Returns, } \\
\text { ASX200 }\end{array}$ & $\begin{array}{l}\text { Monthly } \\
\text { Excess } \\
\text { Returns, } \\
\text { ASX200 }\end{array}$ & $\begin{array}{l}\text { Monthly } \\
\text { Volatility, } \\
\text { ASX200 }\end{array}$ \\
\hline Mean & 0.0000101 & 0.000189 & 0.04071 \\
\hline Maximum & 0.056138 & 0.06866 & 0.17944 \\
\hline Minimum & -0.087207 & -0.139299 & 0.014 \\
\hline Standard Deviation & 0.009916 & 0.037762 & 0.021781 \\
\hline Skewness & -0.457219 & -0.80551 & 2.591128 \\
\hline Kurtosis & 8.774441 & 3.659199 & 13.4341 \\
\hline $\begin{array}{l}\text { Jarque-Bera statistic } \\
\text { (P-value) }\end{array}$ & $\begin{array}{l}6168.133 \\
(0)\end{array}$ & $\begin{array}{l}25.2494 \\
(0.000003)\end{array}$ & $\begin{array}{l}1131.052 \\
(0)\end{array}$ \\
\hline
\end{tabular}

Panel B: Summary statistics of CSSD of betas on ASX200 returns and their logged values

\begin{tabular}{|c|c|c|c|c|c|c|c|c|c|c|}
\hline & \multicolumn{5}{|c|}{ CSSD of betas on ASX200 } & \multicolumn{5}{|c|}{ Log of CSSD of betas on ASX200 } \\
\hline & \multirow[b]{2}{*}{ OLS } & \multicolumn{3}{|c|}{ Quantile } & \multirow[b]{2}{*}{0.95} & \multirow[b]{2}{*}{ OLS } & \multicolumn{4}{|c|}{ Quantile } \\
\hline & & 0.05 & 0.1 & 0.9 & & & 0.05 & 0.1 & 0.9 & 0.95 \\
\hline Mean & 0.804 & 2.143 & 1.280 & 1.397 & 2.141 & -0.259 & 0.669 & 0.187 & 0.279 & 0.694 \\
\hline Maximum & 1.895 & 5.902 & 3.673 & 3.418 & 6.038 & 0.639 & 1.775 & 1.301 & 1.229 & 1.798 \\
\hline Minimum & 0.377 & 0.689 & 0.539 & 0.584 & 0.772 & -0.975 & -0.372 & -0.617 & -0.537 & -0.259 \\
\hline $\begin{array}{l}\text { Standard } \\
\text { Deviation }\end{array}$ & 0.243 & 0.970 & 0.465 & 0.489 & 0.813 & 0.278 & 0.433 & 0.346 & 0.328 & 0.369 \\
\hline Skewness & 1.437 & 1.217 & 1.247 & 1.312 & 1.119 & 0.419 & 0.075 & 0.139 & 0.210 & 0.008 \\
\hline $\begin{array}{l}\text { Kurtosis } \\
\text { Jarque- } \\
\text { Bera } \\
\text { statistic } \\
\text { (P-value) }\end{array}$ & $\begin{array}{c}149.924 \\
\text { (0) }\end{array}$ & $\begin{array}{c}74.585 \\
(0)\end{array}$ & $\begin{array}{c}123.361 \\
(0)\end{array}$ & $\begin{array}{c}110.007 \\
\text { (0) }\end{array}$ & $\begin{array}{c}81.326 \\
(0)\end{array}$ & $\begin{array}{c}7.188 \\
(0.028)\end{array}$ & $\begin{array}{c}0.754 \\
(0.686)\end{array}$ & $\begin{array}{c}1.005 \\
(0.605)\end{array}$ & $\begin{array}{c}1.610 \\
(0.447)\end{array}$ & $\begin{array}{c}0.262 \\
(0.877)\end{array}$ \\
\hline
\end{tabular}

For each month, daily data are used to obtain beta estimates on ASX200 returns using the OLS and the quantile regression methods. These estimated betas are employed for calculating cross-sectional standard deviations.

\subsubsection{Herding towards the market portfolio: Evidence from ordinary least squares betas}

Table 2, Column 2, reports estimation of Models (A1) and (A2) based on OLS betas. In both models, $\sigma_{m \eta}$, the standard deviation of error in the herding variable $H_{m t}=\log \left(1-h_{m t}\right)$, is significant at the $1 \%$ level of significance and suggests the existence of herding towards the market portfolio. Significant $\left|\phi_{m}\right|<1$ values support the stationarity of the process and the 
autoregressive structure used in modelling. Sizable positive values of $\phi_{m}$ show persistence in the herding process. The autocorrelation function of residuals (not provided in this paper) after fitting both models showed no unexplained pattern. A PoSEH value of 34.1\% for Model (A1) shows the amount of variation in $\log -\operatorname{CSSD}\left(b_{\text {imt }}\right)$ due to herding and that the value reduces to $25.9 \%$ for Model (A2), when the effect of monthly market volatility and returns are controlled for. The likelihood and Schwarz Information Criterion (SIC) values suggest that Model (A2) fits better than Model (A1) and imply that part of the variation in log$\operatorname{CSSD}\left(b_{\text {imt }}\right)$ is explained by market volatility, $\log -V_{m}$. The market return $r_{m}$ does not have a significant effect on $\log -\operatorname{CSSD}\left(b_{i m t}\right)$. A significant negative relationship of $\log -V_{m}$ with $\log$ $\operatorname{CSSD}\left(b_{i m t}\right)$ at all quantiles and on the average level means that market volatility reduces the $\operatorname{CSSD}\left(b_{\text {imt }}\right)$. The effect of $r_{m}$ on $\operatorname{CSSD}\left(b_{\text {imt }}\right)$ is variable; it is not significant at the $95^{\text {th }}$ quantile and at the average level.

Table 2

Herding towards the market portfolio: State-Space Models (A1) and (A2) (standard errors are reported in parentheses).

\begin{tabular}{|c|c|c|c|c|c|c|c|c|c|c|}
\hline & Model (A1) & & & & & Model (A2) & & & & \\
\hline & & & Quantile & & & & & Quantile & & \\
\hline & OLS & 0.05 & 0.1 & 0.9 & 0.95 & OLS & 0.05 & 0.1 & 0.9 & 0.95 \\
\hline$\mu_{\mathrm{m}}$ & \begin{tabular}{|l|}
-0.252 \\
$(0.064)^{* * *}$
\end{tabular} & $\begin{array}{l}0.713 \\
(0.118)^{* * *}\end{array}$ & $\begin{array}{l}0.219 \\
(0.101)^{* * *}\end{array}$ & $\begin{array}{l}0.287 \\
(0.083)^{* * *}\end{array}$ & $\begin{array}{l}0.696 \\
(0.068)^{* * *}\end{array}$ & $\mid \begin{array}{l}-1.614 \\
(0.173)^{* * *}\end{array}$ & $\begin{array}{l}-1.820 \\
(0.289)^{* * *}\end{array}$ & $\begin{array}{l}-1.948 \\
(0.254)^{* * *}\end{array}$ & $\begin{array}{l}-1.623 \\
(0.154)^{* * *}\end{array}$ & $\begin{array}{l}-1.682 \\
(0.216)^{* * *}\end{array}$ \\
\hline$\phi_{m}$ & $\begin{array}{l}0.887 \\
(0.047)^{* * * *}\end{array}$ & $\begin{array}{l}0.942 \\
(0.034)^{* * *}\end{array}$ & $\begin{array}{l}0.944 \\
(0.031)^{* * *}\end{array}$ & $\begin{array}{l}0.911 \\
(0.042)^{* * *}\end{array}$ & $\begin{array}{l}0.828 \\
(0.067)^{* * *}\end{array}$ & $\begin{array}{l}0.896 \\
(0.049)^{* * *}\end{array}$ & $\begin{array}{l}0.909 \\
(0.050)^{* * *}\end{array}$ & $\begin{array}{l}0.922 \\
(0.040)^{* * *}\end{array}$ & $\begin{array}{l}0.920 \\
(0.037)^{* * *}\end{array}$ & $\begin{array}{l}0.897 \\
(0.046)^{* * *}\end{array}$ \\
\hline$\sigma_{\mathrm{mv}}$ & $\begin{array}{l}0.185 \\
(0.013)^{* * *}\end{array}$ & $\begin{array}{l}0.325 \\
(0.023)^{* * *}\end{array}$ & $\begin{array}{l}0.250 \\
(0.015)^{* * *}\end{array}$ & $\begin{array}{l}0.207 \\
(0.015)^{* * *}\end{array}$ & $\begin{array}{l}0.233 \\
(0.024)^{* * *}\end{array}$ & $\begin{array}{l}0.164 \\
(0.010)^{* * * *}\end{array}$ & $\begin{array}{l}0.259 \\
(0.02)^{* * *}\end{array}$ & $\begin{array}{l}0.188 \\
(0.013)^{* * *}\end{array}$ & $\begin{array}{l}0.152 \\
(0.009)^{* * *}\end{array}$ & $\begin{array}{l}0.175 \\
(0.015)^{* * *}\end{array}$ \\
\hline$\sigma_{\mathrm{mn}}$ & $\begin{array}{l}0.095 \\
(0.021)^{* * * *}\end{array}$ & $\begin{array}{l}0.097 \\
(0.030)^{* * *}\end{array}$ & $\begin{array}{l}0.079 \\
(0.023)^{* * *}\end{array}$ & $\begin{array}{l}0.103 \\
(0.024)^{* * *}\end{array}$ & $\begin{array}{l}0.159 \\
(0.035)^{* * *}\end{array}$ & $\begin{array}{l}0.072 \\
(0.001)^{* * *}\end{array}$ & $\begin{array}{l}0.097 \\
(0.03)^{* * *}\end{array}$ & $\begin{array}{l}0.073 \\
(0.021)^{* * *}\end{array}$ & $\begin{array}{l}0.079 \\
(0.016)^{* * *}\end{array}$ & $\begin{array}{l}0.095 \\
(0.021)^{* * *}\end{array}$ \\
\hline $\log -V_{m}$ & & & & & & \begin{tabular}{||l}
-0.411 \\
$(0.051)^{* * *}$
\end{tabular} & $\begin{array}{l}-0.757 \\
(0.085)^{* * *}\end{array}$ & $\begin{array}{l}-0.649 \\
(0.074)^{* * *}\end{array}$ & $\begin{array}{l}-0.574 \\
(0.042)^{* * *}\end{array}$ & $\begin{array}{l}-0.717 \\
(0.059)^{* * *}\end{array}$ \\
\hline$r_{m}$ & & & & & & $\mid$\begin{tabular}{||c|}
-0.233 \\
$(0.354)$
\end{tabular} & $\begin{array}{l}-1.138 \\
(0.570)^{* * *}\end{array}$ & $\begin{array}{l}-0.750 \\
(0.407)^{* * *}\end{array}$ & $\begin{array}{l}0.459 \\
(0.286)^{* * *}\end{array}$ & $\begin{array}{l}0.638 \\
(0.452)\end{array}$ \\
\hline $\begin{array}{l}\text { Proportion of signal } \\
\text { explained by } \\
\text { herding: Sigma eta } \\
\text { to SD(log-CSSD- } \\
\text { Betas) }\end{array}$ & 0.341 & 0.224 & 0.229 & 0.314 & 0.430 & 0.259 & 0.224 & 0.210 & 0.241 & 0.258 \\
\hline $\begin{array}{l}\text { Log (Maximum) } \\
\text { likelihood values }\end{array}$ & 10.711 & -84.662 & -33.785 & -12.197 & -49.008 & 40.977 & -44.600 & 17.763 & 46.775 & 17.326 \\
\hline $\begin{array}{c}\text { Schwarz information } \\
\text { criterion }\end{array}$ & -0.001 & 0.953 & 0.444 & 0.228 & 0.596 & -0.251 & 0.605 & -0.019 & -0.309 & -0.014 \\
\hline & \multicolumn{4}{|c|}{ *** represents significance at $1 \%$ level. } & & \multicolumn{4}{|c|}{ **** represents significance at $1 \%$ level. } & \\
\hline
\end{tabular}

Table 2 displays estimation of State-Space Models

(A1): $\log \left[\operatorname{CSSD}\left(b_{i m t}\right)\right]=\mu_{m}^{s}+H_{m t}+v_{m t}^{s} \quad$ and $\quad H_{m t}=\phi_{m} H_{m t-1}+\eta_{m t}$,

(A2): $\log \left[\operatorname{CSSD}\left(b_{\text {imt }}\right)\right]=\mu_{m}^{s}+H_{m t}+c_{m 1} \log \hat{\sigma}_{m t}+c_{m 2} r_{m t}+v_{m t}^{s}$ and $H_{m t}=\phi_{m} H_{m t-1}+\eta_{m t}$,

and the proportion of signal explained by herding based on each model, when the Cross-Sectional Standard Deviations are obtained from betas calculated using the OLS and the quantile regression estimation methods. In column $1, \sigma_{m v}$ and $\sigma_{m \eta}$ represent standard deviations of $v_{m t}^{s}$ and $\eta_{m t}$, respectively. 
Herding towards the market portfolio: State-Space Model (A2), extraction based on OLS betas

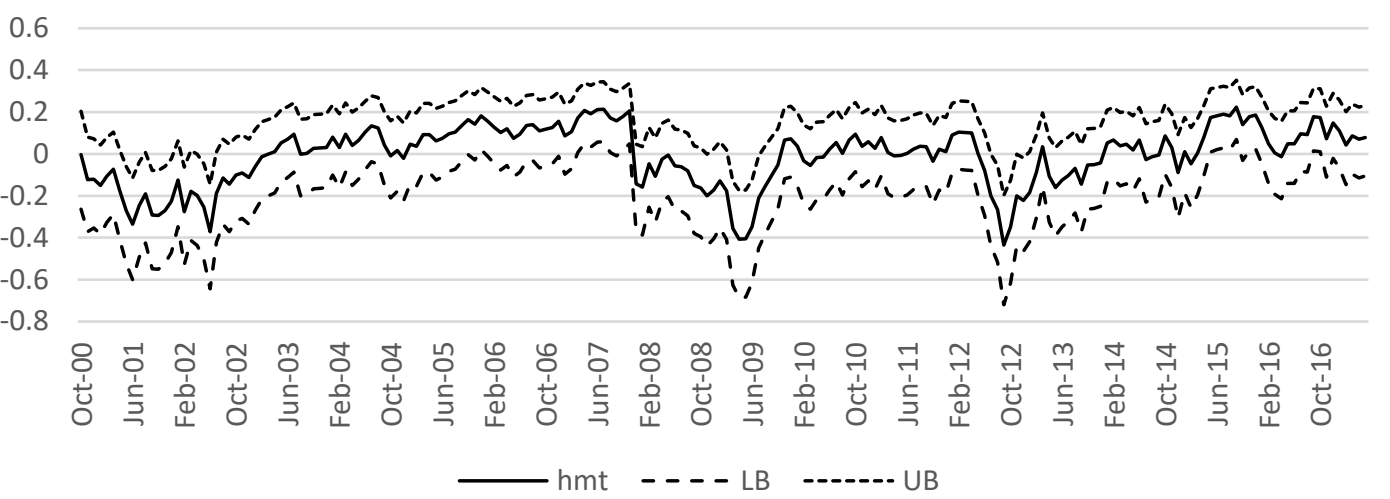

Fig. 4. Herding towards the market portfolio extracted from the OLS based $\operatorname{CSSD}\left(b_{\text {imt }}\right)$ via Model (A2). The graph displays the herding towards the market portfolio component $h_{m t}$ along with the 2 standard error lower and upper bounds.

Figure 4 shows time dynamics of herding towards the market portfolio based on OLS betas and captured by Model (A2). It displays the herding estimates along with two standard errors bounds. The figure shows periods of herding $\left(0<h_{m t}<1\right)$ and adverse herding $\left(h_{m t}<\right.$ 0 ). There are many time periods where not only $0<h_{m t}<1$ or $h_{m t}<0$, but herd estimates are highly significant. Periods January 2001 - July 2002 (the Tech bubble and September 11 attacks on US period), Nov 2008 - July 2009 (the GFC period) and July 2012 - Jan 2013 (the Greek Govt. debt crisis period) display significant adverse herding, and periods Oct 2005 Dec 2007, May 2015 - Dec 2015, Sep 2016 - Oct 2016 show significant herding towards the market portfolio. The upward trend in herding variable extending from July 2002 to September 2007 is interesting as it shows that investors were becoming very confident about the performance of the market and followed the market index without any reservation. The sideways movement of herding variable during the period Dec 2009 to April 2012 reflects investors' lack of confidence in the market performance and uncertainty about the market conditions. It follows that during the period of GFC and the short-selling ban period (September 2008 to May 2009), investors resorted to adverse-herding - a finding that contradicts the Chiang and Zheng (2010) and Bohl et al. (2013) findings based on the Chang et al. (2000) model. Thus, contrary to the common belief portrayed by some previous studies (e.g., Shiller and Pound, 1989; Christie and Huang, 1995) that herd behaviour should show up during turmoil and crisis periods, we observe it during calm 
periods when investors are able to easily predict the market moves and become fearless in following the market. The build-up of longish increasing trend towards a statistically significant herding pattern seen prior to GFC does not persist after the GFC and the presence of adverse herding during the GFC and the short selling ban periods suggests investors became more cautious and risk-averse during these periods. Thus, it follows that Christie and Huang (1995) and CCK (2000) models are geared towards capturing very different patterns compared to the Hwang and Salmon (2004) model.

\subsubsection{Herding towards the market portfolio: Evidence from Quantile regression betas}

The comments made in the preceding section on herding extracted from the SS Models (A1) and (A2) employing the OLS based log-CSSD $\left(b_{i m t}\right)$ can be extended to all model fittings based on quantile regression estimated betas. It is clear that Model (A2) is a better fitting model. While the PoSEH using CSSD of the $90^{\text {th }}$ and $95^{\text {th }}$ quantile betas in Model (A1) are much higher ( $31.4 \%$ and $43.1 \%$, respectively) than using CSSD of the $5^{\text {th }}$ and $10^{\text {th }}$ quantile betas (22.4\% and $22.9 \%$, respectively), this is not true for Model (A2). We observe that the PoSEH with Model (A2) drops considerably at the upper quantiles, indicating that some of the variation in $\log \left[\operatorname{CSSD}\left(b_{i m t}\right)\right]$ is explained by $\log -V_{m}$ and market returns. The negative coefficients of $\log -V_{m}$ at all quantiles are significant at the $1 \%$ level and the coefficients of market returns $r_{m}$ are also highly significant at these quantiles with the exception of the $95^{\text {th }}$ quantile. While the presence of $\log -V_{m}$ and $r_{m}$ has caused reduction in the PoSEH at all quantile levels and the average level (34.1\% to $25.9 \%)$, the impact is maximum at the $95^{\text {th }}$ quantile (43\% to $25.8 \%$ ) and virtually none at the $5^{\text {th }}$ quantile $(22.4 \%$ to $22.4 \%)$. This suggests that market volatility has a substantial impact on betas on high performance days.

Table 3

Correlation between Cross-Sectional Standard Deviations (CSSDs) of betas and herding parameter estimates ' $h_{m t}$ '.

\begin{tabular}{|c|c|c|c|c|c|}
\hline $\begin{array}{c}\text { Method of beta } \\
\text { estimation }\end{array}$ & OLS & $\begin{array}{c}\text { Quantile } \\
\theta=0.05\end{array}$ & $\begin{array}{c}\text { Quantile } \\
\theta=0.10\end{array}$ & $\begin{array}{c}\text { Quantile } \\
\theta=0.90\end{array}$ & $\begin{array}{c}\text { Quantile } \\
\theta=0.95\end{array}$ \\
\hline Model A1 & -0.859 & -0.766 & -0.780 & -0.873 & -0.906 \\
Model A2 & -0.634 & -0.529 & -0.448 & -0.532 & -0.381 \\
\hline
\end{tabular}

This table reports Pearson's correlation coefficients between CSSD of betas and herding estimates ' $h h^{\prime}$ ' extracted from the State-Space Models (A1) and (A2) when CSSDs are based on betas estimated using the OLS and the quantile regression estimation methods. 
Table 3 exhibits correlation between $\operatorname{CSSD}\left(b_{i m t}\right)$ and $h_{m t}$ estimates extracted from Models (A1) and (A2) employing the OLS and quantile regression estimated betas. As per the literature (e.g., Hwang and Salmon, 2004), herding towards the market portfolio should reduce cross-sectional variance of betas; the stronger the herding the higher the reduction in the cross-sectional variance of betas. On the surface, the presence of negative correlations in Table 3 supports this argument. For Model (A1), the correlation coefficient for the $95^{\text {th }}$ quantile is -0.906 and herding explains $43 \%$ of the variation in $\log -\operatorname{CSSD}\left(b_{\text {imt }}\right)$ and $\sigma_{m \eta}$ is $15.87 \%$ (Table 2, Panel A) compared to the correlation coefficient of -0.859 , the PoSEH as $34.1 \%$, and $\sigma_{m \eta}$ equal to $9.48 \%$ for the OLS estimated values. However, Model (A2) yields the correlation and $\sigma_{m \eta}$ values as -0.381 and $9.5 \%$, respectively, for the $95^{\text {th }}$ quantile, and -0.634 and $7.2 \%$ for the OLS based estimates, while the PoSEH values of $25.83 \%$ and $25.93 \%$ in these two situations are virtually the same. This suggests that some of the variation in CSSD of betas and, therefore, in the measurement equation is due to market volatility in returns, i.e., $\log -V_{m}$. Controlling for $\log -V_{m}$ in Model (A2) reduces $\sigma_{m v}$ as well as $\sigma_{m \eta}$. The reduction in $\sigma_{m v}$ is about $6 \%$ at all levels of the return distribution, and the PoSEH settles to about $22 \%$ to $26 \%$, implying that some of the variation in the crosssectional variance of betas at the extreme quantiles may be due to factors other than herding. A significant negative relationship of $\log -V_{m}$ with $\log -\operatorname{CSSD}\left(b_{\text {imt }}\right)$ (Table 2 , Model (A2)) at all quantiles and on the average level means that market volatility reduces the $\operatorname{CSSD}\left(b_{\text {imt }}\right)$; it impacts the entire distribution of $\operatorname{CSSD}\left(b_{\text {imt }}\right)$. It could be that an increase in market volatility creates uncertainty among the market participants and they start to herd back to fundamentals, a sign of risk-aversion, and this causes reduction in the crosssectional variance of betas.

We now discuss herd dynamics based on the better fitting Model (A2). Figures 5(a) and 5(b) display herd dynamics extracted from Model (A2) employing CSSDs of betas estimated at the $5 \%$ and $95 \%$ quantiles, respectively. These graphs show many periods of herding and adverse herding. There is an increasing trend in herding movement leading up to the warning signs of the GFC and then results in adverse herding. Herding takes place during calmer periods and adverse herding during turmoil periods. After the GFC, the herd movement is mostly sideways and horizontal in nature and not significant, implying 
Herding towards market portfolio: State-Space Model (A2), extraction based on quantile 0.05 betas

1

0.5

0

$-0.5$

$-1$

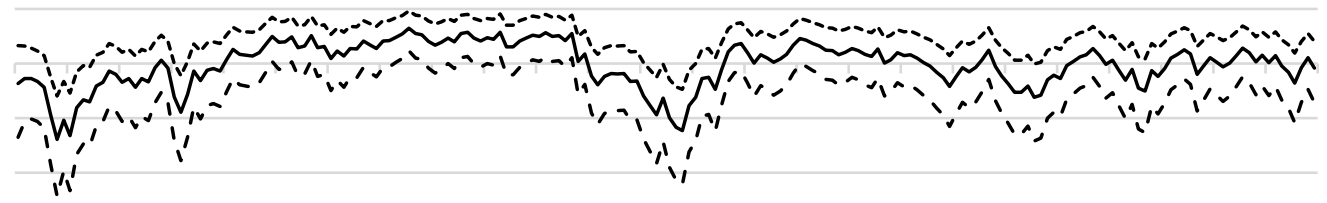

$-1.5$

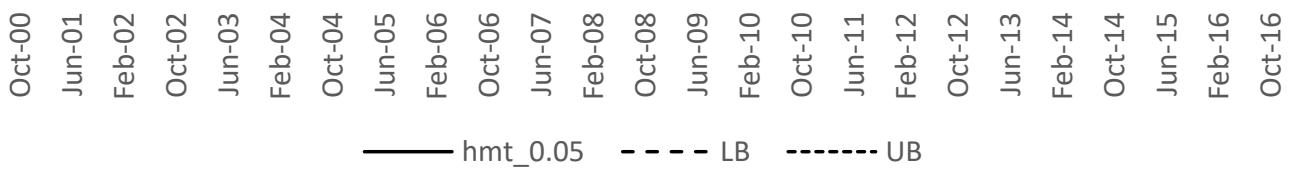

Fig. 5(a). Herding towards the market portfolio using quantile 0.05 betas in State-Space Model (A2); $h_{m t \_0.05}$ is the herding component, and LB and UB the 2 standard error lower and upper bounds.

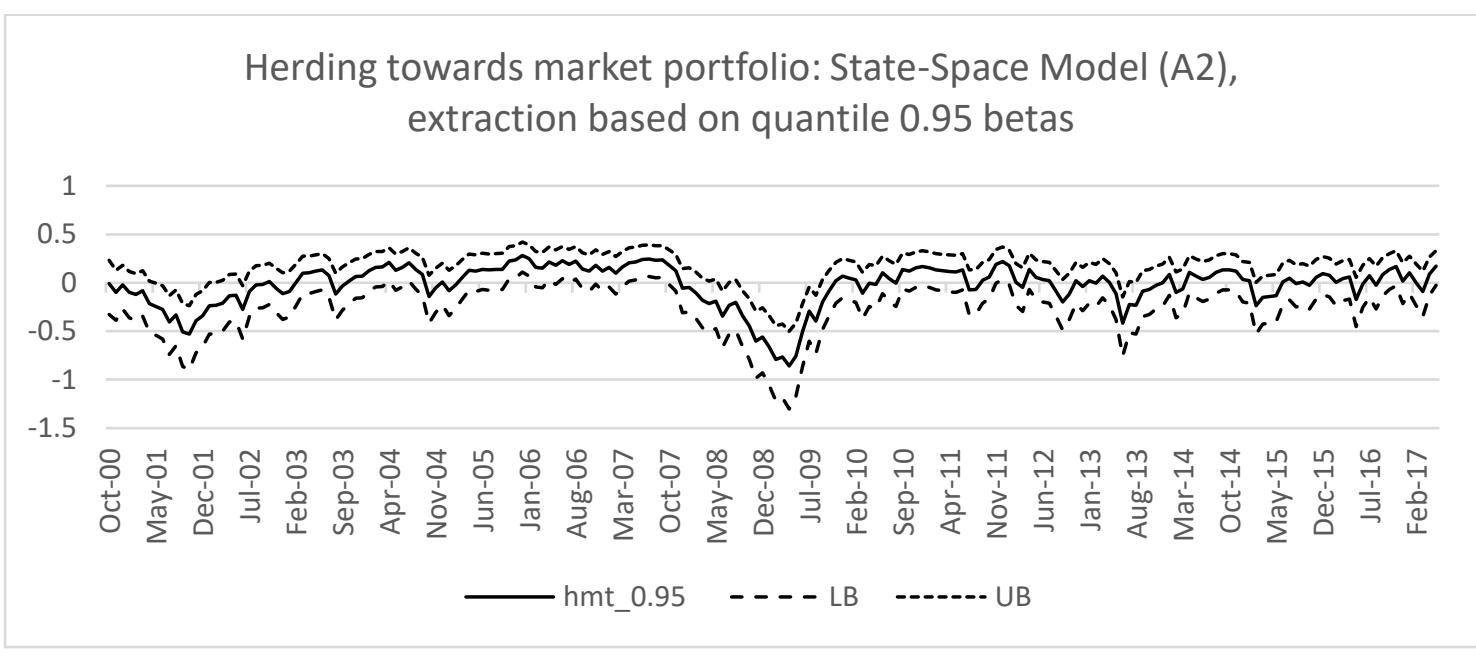

Fig. 5(b). Herding towards the market portfolio using quantile 0.95 betas in State-Space Model (A2); $h_{m t} 0.95$ is the herding component, and LB and UB the 2 standard error lower and upper bounds.

uncertainty. Although there is a lot of similarity in herd dynamics based on OLS and quantile regression estimated betas, the intensity of herding and adverse herding behaviour is much stronger at the $5^{\text {th }}$ and $95^{\text {th }}$ quantiles. The dip due to adverse herding is much deeper during the GFC and the short-selling ban periods. This finding contradicts the Bohl et al. (2013) finding based on the Chang et al. (2000) model that in Australia herding took place during the short-selling ban period.

The presence of herding and adverse herding at the extreme quantiles suggests that such behaviour can emerge during the worst and the best performance days of stock returns. It can be inferred from the existence of significant adverse herding during the crisis 
periods that investors move away from herding, a sign of risk-aversion, to cope with the unpredictable market movements.

\subsection{Herding towards the Market portfolio, Book-to-Market and Trading Volume factors: The Linear Factor Model}

We now examine investor herd behaviour and risk profiles link using the linear factor model described by Model (B), and factor sensitivities other than the systematic risk. We start by describing the characteristics of CSSDs of betas - the factor loadings of excess market returns, Book-to-market (BM) ratios and Trading volume (TR), obtained by fitting Model (B). Table 4 displays summary statistics of CSSDs of betas obtained by using the OLS and the quantile regression methods.

\subsubsection{Characteristics of Cross-Sectional Standard Deviations of betas from the Linear Factor Model}

We start by comparing the CSSDs of OLS betas for excess market returns, obtained by fitting Models $(A)$ and (B). Figure 6 graphs the time series of CSSDs of market betas $\left(\operatorname{CSSD}\left(b_{m t}\right)\right)$ for Models (A) and (B). It shows that starting from about January 2006 the two series start to separate from each other; the $\operatorname{CSSD}\left(b_{m t}\right)$ values from Model $(\mathrm{B})$ are generally larger than Model (A) on a monthly basis. The summary statistics of $\operatorname{CSSD}\left(b_{m t}\right)$ series for Model $(\mathrm{A})$ (Table 1, Panel B, Column 2) and Model (B) (Table 4, Column 2), reveals that Model (B) based mean, maximum and minimum values of $\operatorname{CSSD}\left(b_{m t}\right)$, when the effects of BM and TR are controlled for, are larger than the corresponding Model $(A)$ values, but the standard deviation value of $\operatorname{CSSD}\left(b_{m t}\right)$ is lower. Larger mean, maximum and minimum values of $\operatorname{CSSD}\left(b_{m t}\right)$ imply that there is more variation in market beta estimates for individual stocks on a monthly basis. This could be due to the presence of other sources of information like $\mathrm{BM}$ and TR that investors resort to for their decision making in response to the varying market conditions on a daily basis, and, therefore, adding variations in individual monthly betas. Smaller standard deviation of $\operatorname{CSSD}\left(b_{m t}\right)$ values indicates similarity and stability in market betas resulting from Model (B). The usage of such betas should, therefore, extract more stable herding movement estimates from the SS models. The positive skew and kurtosis in $\operatorname{CSSD}\left(b_{m t}\right)$ series is also much larger for Model (B) compared to Model (A); the 
series $\log -\operatorname{CSSD}\left(b_{m t}\right)$ is positively skewed, leptokurtic and non-Gaussian, implying concentration of $\log \operatorname{CSSD}\left(b_{m t}\right)$ values in the left tail. We, therefore, expect the quantile regression estimated betas to perform better than the OLS betas and the resulting herding pattern to be different from the one observed from Model $(A)$.

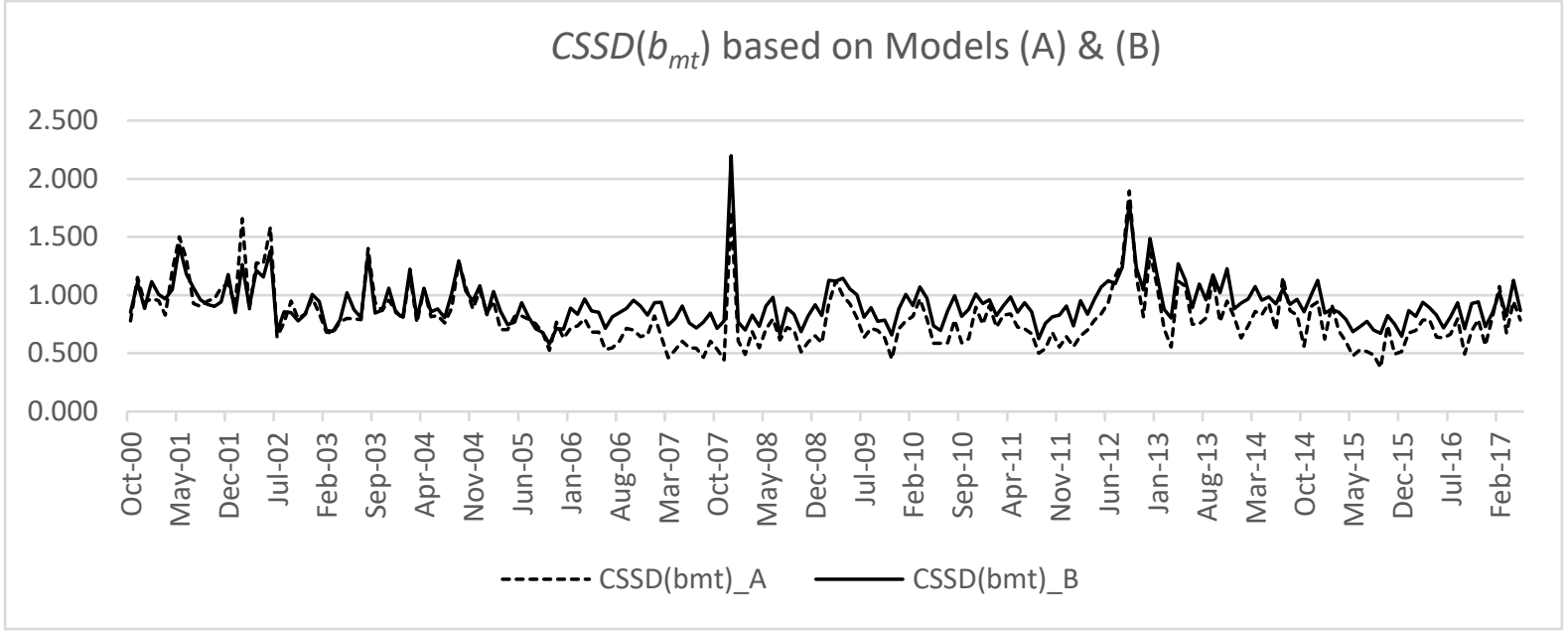

Fig. 6. Monthly Cross-Sectional Standard Deviations (CSSDs) of market betas from Models (A) and (B). The graph demonstrates that the CSSDs of betas based on Models (A) and (B) are influenced by other factors and are not identical.

Now referring to Panel A in Table 4 we observe that OLS based CSSDs of BM betas series and its logged values are non-Gaussian; they are positively skewed and leptokurtic. However, the CSSD of TR beta series and its logged values are both Gaussian. Panel B in Table 4 reports descriptive statistics for CSSDs of quantile 0.05 betas and Panel C for quantile 0.95. The mean, maximum, minimum and standard deviation of monthly CSSDs of quantile 0.05 market betas are larger than the corresponding OLS values. However, the skewness and kurtosis values for this series are much smaller than the OLS based values; the series is non-Gaussian but its logged values series is Gaussian. While these comments can be replicated for mean, maximum, minimum and standard deviation of monthly CSSDs of quantile $0.05 \mathrm{BM}$ betas, it is not true for skewness and kurtosis. The $\operatorname{CSSD}\left(b_{B M t}\right)$ series and its logged values are not Gaussian. The $\operatorname{CSSD}\left(b_{T R t}\right)$ series has much smaller mean, maximum, minimum and standard deviation values than the OLS based values in Panel A, but the series is more positively skewed and leptokurtic. This series and its logged values are non-Gaussian as well. Comparing values in Panels $A$ and $C$, the comments made on the basis of quantile 0.05 can be replicated for quantile 0.95 . Observing differences in CSSDs of OLS and quantile 
regression estimated betas reported in Panels $A, B$ and $C$, we expect the herding patterns based on these series to be different.

Table 4

Descriptive Statistics of CSSDs of betas based on the Linear factor Model (B).

\begin{tabular}{|c|c|c|c|c|c|c|}
\hline & \multicolumn{3}{|c|}{ CSSD of betas } & \multicolumn{3}{|c|}{ Log-CSSD of betas } \\
\hline $\begin{array}{l}\text { Panel A: The } \\
\text { OLS betas }\end{array}$ & $\begin{array}{c}\text { XMkt- } \\
\text { Ret }\end{array}$ & $\begin{array}{c}\text { Book- } \\
\text { to- } \\
\text { Market }\end{array}$ & $\begin{array}{l}\text { Trading } \\
\text { Volume }\end{array}$ & $\begin{array}{c}\text { XMkt- } \\
\text { Ret }\end{array}$ & $\begin{array}{c}\text { Book- } \\
\text { to- } \\
\text { Market }\end{array}$ & $\begin{array}{l}\text { Trading } \\
\text { Volume }\end{array}$ \\
\hline Mean & 0.923 & 1.281 & 0.453 & -0.099 & 0.098 & -0.793 \\
\hline Maximum & 2.198 & 6.246 & 0.508 & 0.787 & 1.832 & -0.678 \\
\hline Minimum & 0.580 & 0.535 & 0.405 & -0.546 & -0.625 & -0.905 \\
\hline $\begin{array}{l}\text { Standard } \\
\text { Deviation }\end{array}$ & 0.195 & 0.899 & 0.020 & 0.188 & 0.497 & 0.045 \\
\hline Skewness & 2.203 & 2.726 & 0.233 & 0.894 & 1.233 & 0.120 \\
\hline Kurtosis & 12.934 & 11.590 & 2.752 & 5.348 & 4.251 & 2.692 \\
\hline $\begin{array}{l}\text { Jaque-Bera } \\
\text { statistic } \\
\text { (P-value) }\end{array}$ & $\begin{array}{l}984.106 \\
(0)\end{array}$ & $\begin{array}{c}862.555 \\
(0)\end{array}$ & $\begin{array}{c}2.323 \\
(0.313)\end{array}$ & $\begin{array}{c}72.61 \\
(0)\end{array}$ & $\begin{array}{c}63.716 \\
(0)\end{array}$ & $\begin{array}{c}1.27 \\
(0.53)\end{array}$ \\
\hline
\end{tabular}

Panel B: The Quantile 0.05 betas

\begin{tabular}{|c|c|c|c|c|c|c|}
\hline Mean & 1.301 & 1.672 & 0.009 & 0.228 & 0.378 & -4.832 \\
\hline Maximum & 2.508 & 10.917 & 0.040 & 0.920 & 2.390 & -3.227 \\
\hline Minimum & 0.664 & 0.678 & 0.004 & -0.410 & -0.389 & -5.573 \\
\hline $\begin{array}{l}\text { Standard } \\
\text { Deviation }\end{array}$ & 0.356 & 1.187 & 0.004 & 0.263 & 0.468 & 0.367 \\
\hline Skewness & 0.929 & 3.890 & 3.197 & 0.201 & 1.297 & 0.967 \\
\hline Kurtosis & 3.906 & 23.946 & 20.633 & 2.844 & 5.347 & 4.416 \\
\hline $\begin{array}{l}\text { Jaque-Bera } \\
\text { statistic } \\
\text { (P-value) }\end{array}$ & $\begin{array}{c}35.643 \\
(0)\end{array}$ & $\begin{array}{c}4160.779 \\
(0)\end{array}$ & $\begin{array}{c}2931.53 \\
(0)\end{array}$ & $\begin{array}{l}1.553 \\
(0.46)\end{array}$ & $\begin{array}{c}101.991 \\
(0)\end{array}$ & $\begin{array}{c}47.883 \\
(0)\end{array}$ \\
\hline
\end{tabular}

Panel C: The Quantile 0.95 betas

\begin{tabular}{l|r|r|r||r|r|r}
\hline Mean & 1.334 & 1.747 & 0.009 & 0.262 & 0.417 & -4.758 \\
Maximum & 2.796 & 12.135 & 0.035 & 1.032 & 2.496 & -3.345 \\
Minimum & 0.757 & 0.663 & 0.004 & -0.275 & -0.410 & -5.493 \\
Standard & & & & & & \\
Deviation & 0.354 & 1.256 & 0.004 & 0.251 & 0.479 & 0.381 \\
Skewness & 1.088 & 4.025 & 2.324 & 0.342 & 1.249 & 1.027 \\
Kurtosis & 4.487 & 27.295 & 10.139 & 2.906 & 4.918 & 3.920 \\
Jaque-Bera & 57.862 & 5458.633 & 604.809 & 3.973 & 82.618 & 42.192 \\
Statistic & $(0)$ & $(0)$ & $(0)$ & $(0.137)$ & $(0)$ & $(0)$ \\
(P-value) & & & & & & \\
\hline
\end{tabular}

Table 4 reports descriptive statistics of CSSDs of betas obtained from the Linear Factor Model (B) estimated at the average level and the 5th and 95th quantiles via the OLS and the quantile regression methods. 


\subsubsection{Herding towards Market portfolio, Book-to-Market and Trading Volume factors:}

Evidence from the OLS estimated betas

Figure 7 displays the time series graphs of CSSDs of market, BM and TR betas obtained by OLS estimation of the linear factor Model (B). As the three series show vast variations in intensity and do not always peak in the same time period, we expect variations in the level of herding towards each factor. These variations should reveal investors' risk tendencies during calmer and turbulent periods.

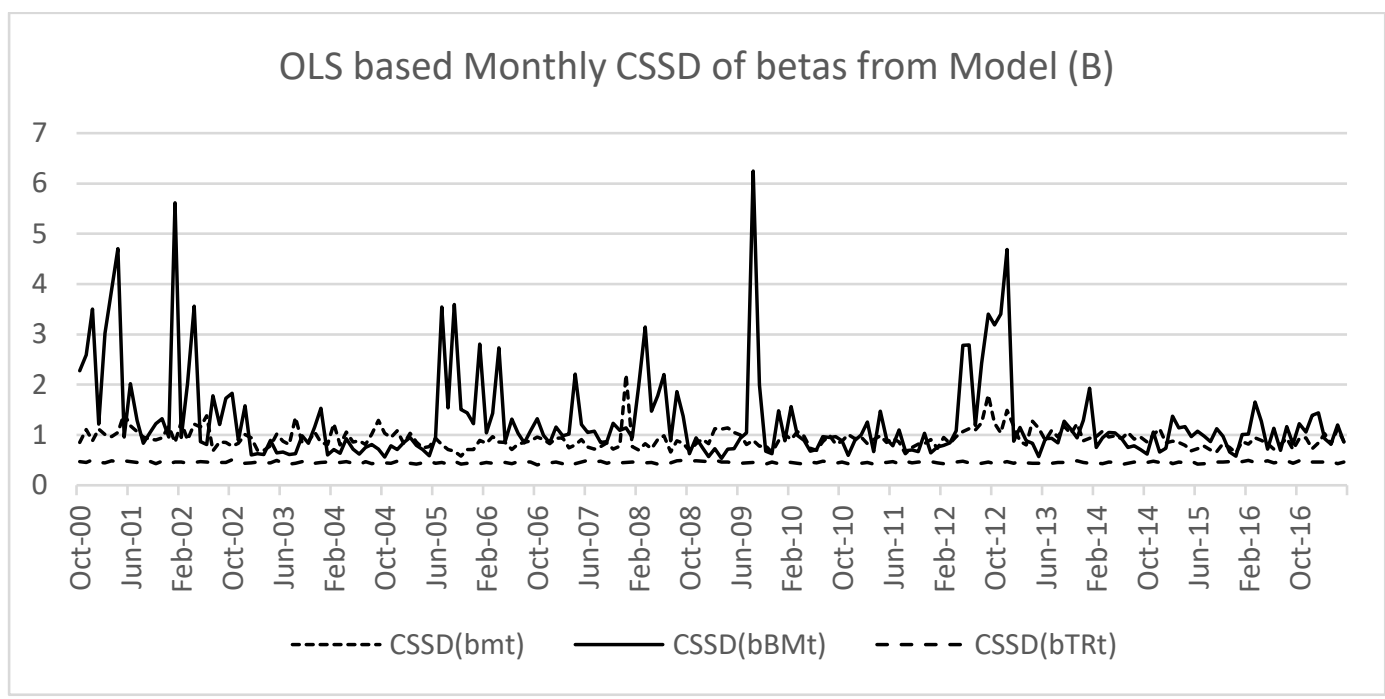

Fig. 7. Comparison of monthly Cross-Sectional Standard Deviations of betas - the Model (B) factor sensitivities. The graph shows CSSDs of betas - the sensitivities of stock returns to market portfolio, Book-toMarket and Trading volume within the linear factor model estimated using the OLS method. The three series behave quite differently and should yield differences in herding behaviour.

Table 5 reports the estimation of State-Space models employed for extracting herd behaviour towards the market portfolio, BM, and TR factors from the log-CSSD of OLS estimated betas. Panel A in Table 5 reports the estimation of SS Models (B11), (B21) and (B31) and Panel B the estimation of Models (B12), (B22) and (B32). It follows from Panels A and $B$ that the herding parameter $\phi$ is highly significant for all factors. However, the variance $\sigma_{. \eta}^{2}$ of the herding variable is significant in all models and for all factors but for trading volume, suggesting a weak tendency of herding towards the TR factor. Viewing the Log (Maximum likelihood) and the Schwarz Information Criterion values in Table 5 for models in Panels A and B for all factors, it follows that models representing herding towards the market portfolio and BM factors perform better when the market volatility and market returns are incorporated in the model. However, this is not true for TR-herding. The PoSEH 
towards each factor weakens by the presence of market volatility and market returns as exogenous variables in the model, implying that market volatility is an important influencing variable impacting investor herding behaviour. The market volatility variable, $\log -V_{m}$, is significant in State Space Models for herding towards the market portfolio and BM, but not for TR. Variable market return, $r_{m}$, is not significant in any of the State Space model fittings. In the following sections, we discuss herding behaviour towards each factor focusing mainly on a better fitting model for each factor.

\section{Table 5}

Estimates of the State-Space Models for herding towards the market portfolio, Book-to-Market \& Trading Volume factors using OLS betas (standard errors in parentheses).

\begin{tabular}{|c|c|c|c|c|c|c|}
\hline & Panel A & & & Panel B & & \\
\hline & $\begin{array}{c}\text { Market Portfolio } \\
\text { (Model B11) }\end{array}$ & $\begin{array}{c}\text { Book-to-Market } \\
\text { (Model B21) }\end{array}$ & $\begin{array}{l}\text { Trading Volume } \\
\text { (Model B31) }\end{array}$ & $\begin{array}{c}\text { Market Portfolio } \\
\text { (Model B12) }\end{array}$ & $\begin{array}{c}\text { Book-to-Market } \\
\text { (Model B22) }\end{array}$ & $\begin{array}{c}\text { Trading Volume } \\
\text { (Model B32) }\end{array}$ \\
\hline$\mu$. & $-0.098(0.034) * * *$ & $0.108(0.107)$ & $-0.792(0.005)^{* * *}$ & $-1.103(0.130)^{* * *}$ & $-0.621(0.428)$ & $-0.741(0.035)^{* * *}$ \\
\hline$\phi$ & $0.841(0.076)^{* * *}$ & $0.801(0.078)^{* * *}$ & $0.911(0.110)^{* * *}$ & $0.917(0.048)^{* * *}$ & $0.829(0.072)^{* * *}$ & $0.953(0.083)^{* * *}$ \\
\hline$\sigma \cdot v$ & $0.145(0.009)^{* * *}$ & $0.326(0.036) * * *$ & $0.043(0.003)^{* * *}$ & $0.128(0.008)^{* * *}$ & $0.328(0.032) * * *$ & $0.043(0.003)^{* * *}$ \\
\hline$\sigma_{. \eta}$ & $0.064(0.019) * * *$ & $0.228(0.055)^{* * *}$ & $0.005(0.008)$ & $0.048(0.015)^{* * *}$ & $0.210(0.050)^{* * *}$ & $0.003(0.007)$ \\
\hline $\log -V_{m}$ & & & & $\begin{array}{l}-0.303 \\
(0.037)^{* * *}\end{array}$ & $-0.221(0.119)^{*}$ & $0.015(0.010)$ \\
\hline$r_{m}$ & & & & $-0.349(0.318)$ & $0.039(0.922)$ & $-0.149(0.094)$ \\
\hline $\begin{array}{l}\text { Proportion of signal } \\
\text { explained by herding: } \\
\text { Sigma eta to SD(log-CSSD- } \\
\text { Betas) }\end{array}$ & 0.342 & 0.453 & 0.123 & 0.257 & 0.422 & 0.067 \\
\hline $\begin{array}{l}\text { Log (Maximum) likelihood } \\
\text { values }\end{array}$ & 68.771 & -115.742 & 339.390 & 343.626 & 96.076 & -113.536 \\
\hline $\begin{array}{l}\text { Schwarz information } \\
\text { criterion }\end{array}$ & -0.582 & 1.263 & -3.288 & -3.277 & -0.802 & 1.294 \\
\hline & \multicolumn{3}{|c|}{$* * *$ represents significance at $1 \%$ level. } & \multicolumn{3}{|c|}{$* * *$ represents significance at $1 \%$ level; * at $10 \%$} \\
\hline
\end{tabular}

Panel A in Table 5 displays the estimation of the State-Space Models (B11), (B21) and (B31) employed in extracting herding towards the Market Portfolio, Book-to-Market and Trading Volume factors, and the proportion of herding explained by each factor. Panel B exhibits the estimation of the State-Space Models (B12), (B22) and (B32) used in extracting herding towards the Market Portfolio, Book-to-Market and Trading Volume factors, and the proportion of herding explained by each factor. All State-Space models are based on Cross-Sectional Standard Deviations of OLS betas. In column 1, $\sigma_{. v}$ and $\sigma_{. \eta}$ represent standard deviations of $v_{. t}^{S}$ and $\eta_{. t}$, respectively.

5.2.2(a) Herding towards the market portfolio: State-Space Models (B11) and (B12) employing CSSDs of OLS betas

Columns 2 in Panels A and B of Table 5 display estimation of Models (B11) and (B12). It follows that the market volatility, $\log -V_{m}$, has a significant impact on the proportion of variation explained by herding towards the market portfolio. The PoSEH drops from $34.16 \%$ 
for Model (B11) to $25.69 \%$ for Model (B12) after incorporating ' $\log -V_{m}{ }^{\prime}$ as an exogenous variable. Figure 8 displays herd dynamics based on Model (B12). There is a positive trend in the herding coefficient up to about December 2005, apparently the mining boom period in Australia, it plateaus and then results in adverse herding between November 2007 and September 2009 - the GFC and short-selling ban periods in Australia. The herding movement towards the market portfolio is sideways between December 2009 and June 2012 and then results in adverse herding. A positive trend in the herding coefficient emerges again starting from April 2013 to May 2017, but it does not achieve a statistical significance. It follows from the time series pattern in Figure 8 that investors display herd behaviour during calmer periods of the market when investors have confidence in the future state of the market, and adverse herding during periods of uncertainty. Thus, it can be inferred that investors in the Australian market are basically risk-wary; they follow the movements of the market portfolio but with a great caution.

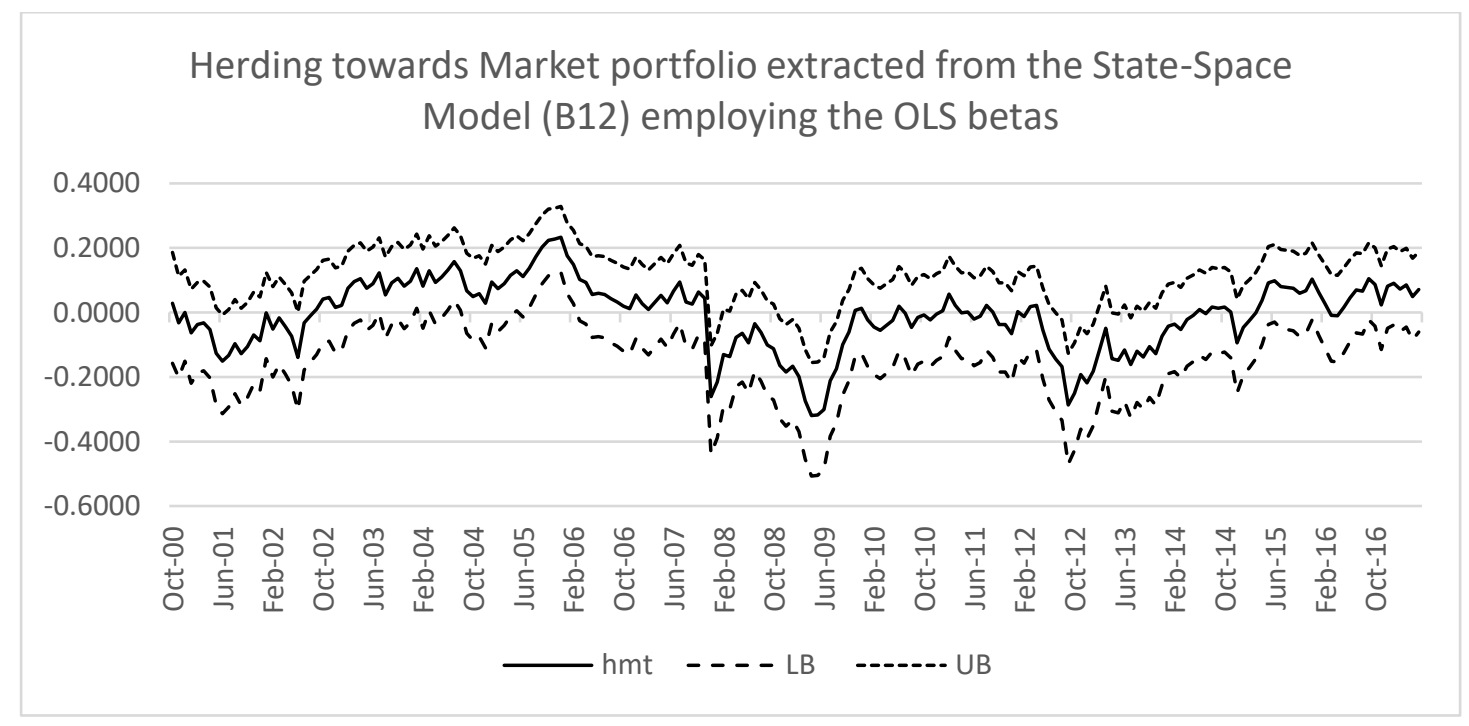

Fig. 8. Herd dynamics towards the market portfolio based on the OLS betas from the Linear Factor Model used in the State-Space Model (B12); LB and UB are the two standard error lower and upper bounds on $h_{m t}$.

5.2.2(b) Herding towards Book-to-market factor: State-Space Models (B21) and (B22) employing CSSDs of OLS betas

Columns 3 in Panels A and B of Table 5 display estimation of Models (B21) and (B22). The PoSEH towards the BM factor is $45.26 \%$ for Model (B21) and $42.22 \%$ for Model (B22); the presence of variables ' $\log -V_{m}$ ' and ' $r_{m}$ ' in Model (B22) has not caused much reduction in the PoSEH. As pointed out earlier, Model (B22) is a better fitting model than Model (B21). The 
explanatory variable 'log- $V_{m}$ ' has a negative but a mild effect on $\log -\operatorname{CSSD}\left(b_{i B M t}\right)$, and accounts for only a small amount of variation in $\log -\operatorname{CSSD}\left(b_{i B M t}\right)$.

Figure 9 displays time series dynamics of herding towards the BM factor. There are many time periods showing incidents of herding and adverse-herding. However, the number of adverse-herding episodes are more frequent than observed for herding towards the market portfolio, suggesting investors' efforts to adjust to the changing market conditions or perceived upcoming turbulent periods and/ or bad news. Upward trending pattern in herding coefficients is less persistent and short lived compared to the case of herding towards the market portfolio; the movements are either sideways or in adverse-herding mode that suggests the presence of a risk-aversion attitude among investors.

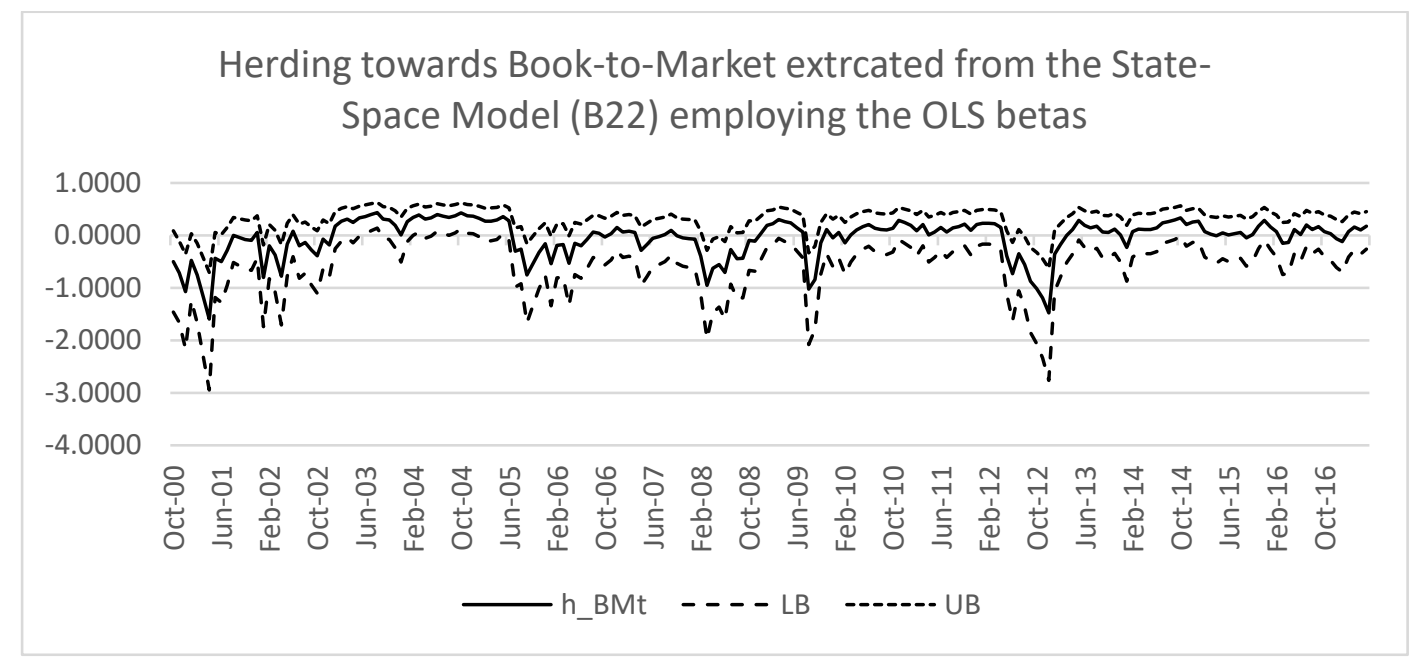

Fig. 9. Herd dynamics towards Book-to-Market factor based on the OLS betas from the Linear Factor Model used in the State-Space Model (B22); LB and UB are the two standard error lower and upper bounds on $h \_B M t$.

5.2.2(c) Herding towards trading volume: State-Space Models (B31) and (B32) employing CSSDs of OLS betas

We observed in Figure 7 that the time series movements in $\operatorname{CSSD}\left(b_{m t}\right), \operatorname{CSSD}\left(b_{B M t}\right)$ and $\operatorname{CSSD}\left(b_{T R t}\right)$ are quite different and we expect variation in herding behaviour towards each factor. Columns 4 in Panels A and B of Table 5 show estimation of Models (B31) and (B32). The standard deviation $\sigma_{.} \eta$ of herding variable towards the trading volume factor is very close to zero, indicating that there is weak to no herding towards the trading volume factor. The proportion of signal explained by herding is just $12.26 \%$ based on Model (B31) that drops to $6.73 \%$ for Model (B32), when the effect of market volatility has been controlled for. 
Figures 10 (a) and 10 (b) graph herd dynamics based on Models (B31) and (B32). These graphs show that at the average level there is no statistically significant herding towards the trading volume at any time during our study period of 17 years. There is a slight increasing trend in the herding coefficients before the GFC, but they do not achieve statistical significance. There is inclination towards adverse herding during the GFC period, but it is not statistically significant. Bearing in mind that low and high trading volumes reflect a response due to very different market conditions, the lack of statistical significant herding towards the trading volume can be interpreted as investors being informed, rational and risk-averse, and do not get swayed by changes in trading volume, at least on average.

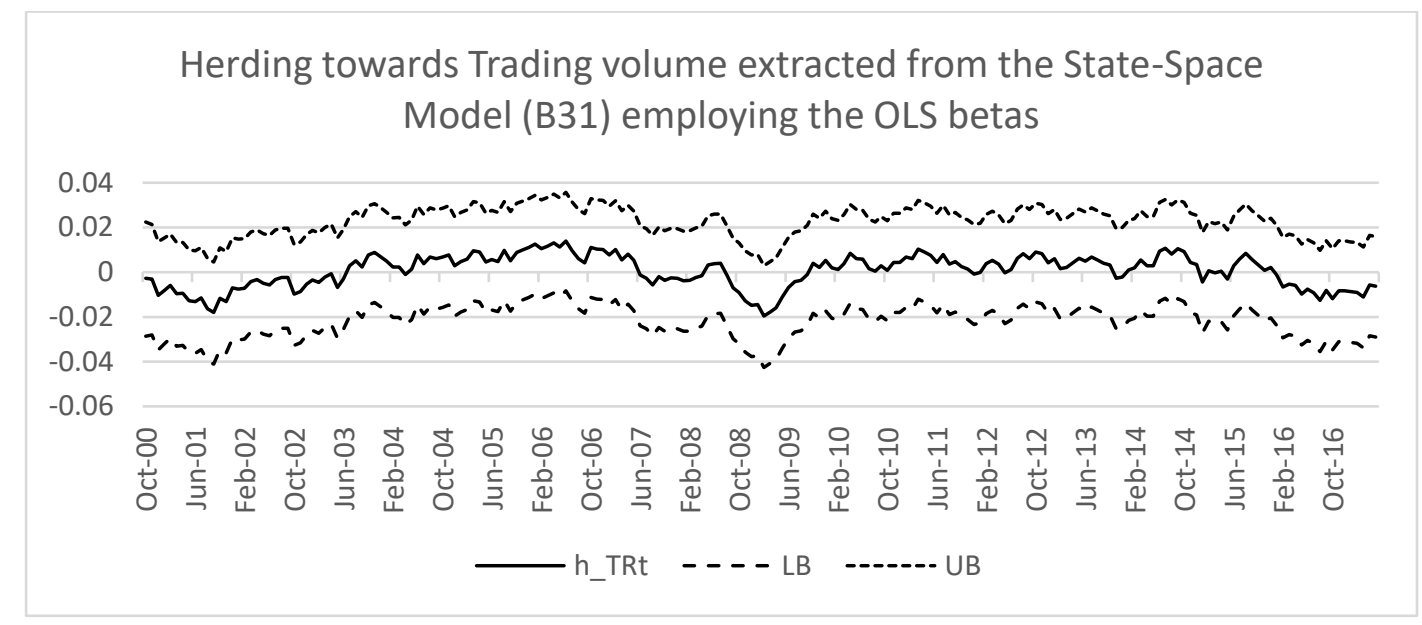

Fig. 10 (a). Herd dynamics towards the trading volume based on the OLS betas from the Linear Factor Model used in the State-Space Model (B31); LB and UB are the two standard error lower and upper bounds on $h_{-}$TRt.

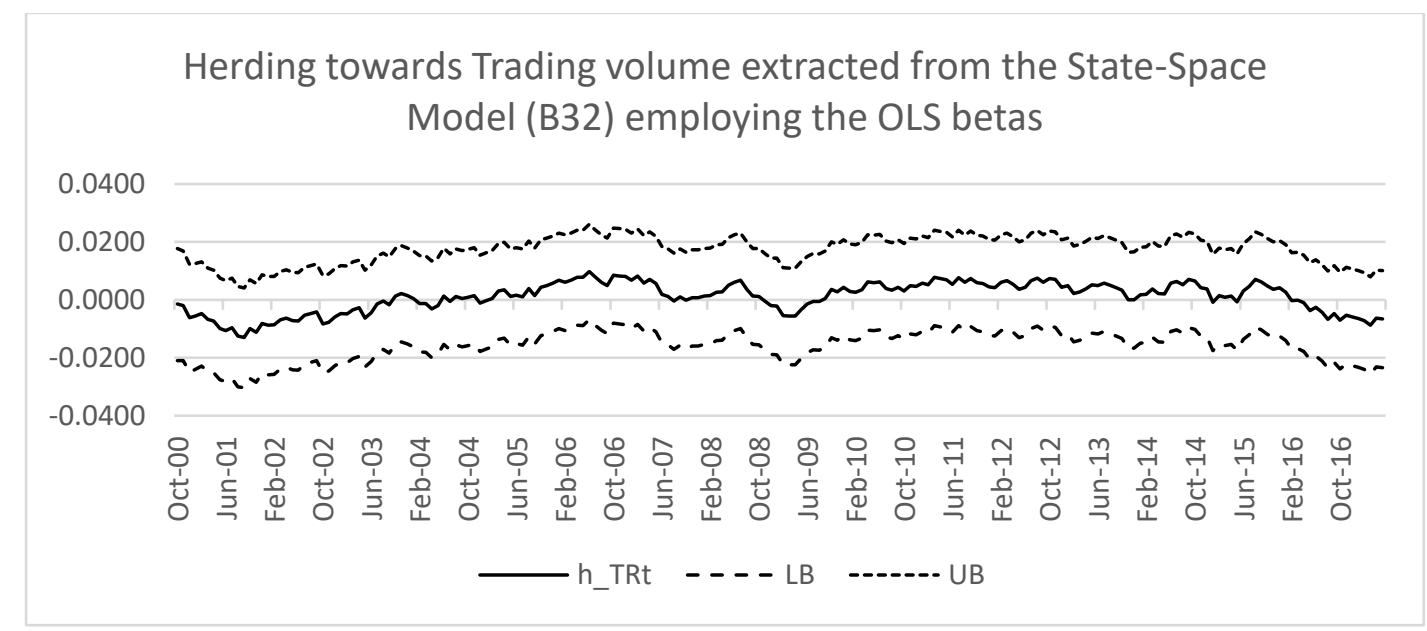

Fig. 10 (b). Herd dynamics towards the trading volume based on the OLS betas from the Linear Factor Model used in the State-Space Model (B32); LB and UB are the two standard error lower and upper bounds. 


\subsubsection{Herding towards Market portfolio, Book-to-Market and Trading Volume factors:}

Evidence from the quantile-regression estimated betas

This section discusses herd behaviour based on the linear factor Model (B) when estimated using the quantile regression method focusing on quantiles 0.05 and 0.95 . Panel A in Table 6 reports the estimation of SS Models (B11), (B21) and (B31) and Panel B details SS Models (B12), (B22) and (B32) employed in extracting herd behaviour towards the Market portfolio, Book-to-Market and Trading volume factors. Figures 11(a) - 13(b) show herd dynamics over time based on the better fitting models for each factor at quantiles 0.05 and 0.95 . We now discuss the herding pattern for each factor.

An inspection of the models in Panels A and B reveals that the herding parameter $\phi$ is highly significant in each model. However, the log (maximum) likelihood and the Schwarz information criterion show that State-Space Models (B11), (B21) and (B31) in Panel A are better performing than Models (B12), (B22) and (B32) in Panel B. This observation is further supported by the fact that standard deviations ' $\sigma_{. \eta}$ ' for all Panel B models are near zero implying virtually no herding towards each factor based on these models; the explanatory variables 'log- $V_{m}$ ' and ' $r_{m}$ ' have a negative and highly significant relationship with log$\operatorname{CSSD}(b . t)$, and are able to explain most of the variation in $\log \operatorname{CSSD}(b . t)$ in the presence of each factor, and not much explaining left for herding. It seems that while small levels of market volatility are perceived as investment opportunities by investors and herding continues, the extreme volatility is seen as a danger sign making investors lose confidence in the market and herd behaviour comes to a near halt. However, such pattern was not observed when OLS based betas were employed in the linear factor model. Table 7 lists the POSEH towards each factor based on a better fitting State-Space model employing the linear factor model betas. We now discuss herding towards each factor separately. 
Table 6

Estimates of State-Space Models for herding towards the market portfolio, Book-to-Market and Trading Volume factors using the quantile regression estimated betas (standard errors in parentheses).

\begin{tabular}{|c|c|c|c|c|c|c|c|c|c|c|c|c|}
\hline & & & Panel A & & & & & & Panel B & & & \\
\hline & \multicolumn{3}{|c|}{ Quantile 0.05} & \multicolumn{3}{|c|}{ Quantile 0.95} & \multicolumn{2}{|r|}{ Quantile 0.05} & & \multicolumn{3}{|c|}{ Quantile 0.95} \\
\hline & $\begin{array}{c}\text { Market } \\
\text { Portfolio } \\
\text { (Model B11) }\end{array}$ & $\begin{array}{c}\text { Book-to- } \\
\text { Market } \\
\text { (Model B21) }\end{array}$ & \begin{tabular}{|c||} 
Trading \\
Volume (Model \\
B31)
\end{tabular} & $\begin{array}{c}\text { Market } \\
\text { Portfolio } \\
\text { (Model B11) }\end{array}$ & $\begin{array}{c}\text { Book-to- } \\
\text { Market } \\
\text { (Model B21) }\end{array}$ & $\begin{array}{c}\text { Trading } \\
\text { Volume } \\
\text { (Model B31) }\end{array}$ & $\begin{array}{c}\text { Market } \\
\text { Portfolio } \\
\text { (Model B12) }\end{array}$ & $\begin{array}{c}\text { Book-to- } \\
\text { Market } \\
\text { (Model B22) }\end{array}$ & $\begin{array}{c}\text { Trading } \\
\text { Volume } \\
\text { (Model B32) }\end{array}$ & $\begin{array}{c}\text { Market } \\
\text { Portfolio } \\
\text { (Model B12) }\end{array}$ & $\begin{array}{c}\text { Book-to- } \\
\text { Market } \\
\text { (Model B22) }\end{array}$ & $\begin{array}{c}\text { Trading } \\
\text { Volume } \\
\text { (Model B32) }\end{array}$ \\
\hline$\mu$. & $\begin{array}{l}0.234 \\
(0.062)^{* * *}\end{array}$ & $\begin{array}{l}0.412 \\
(0.120)^{* * *}\end{array}$ & $\begin{array}{l}-4.793 \\
(0.133)^{* * *}\end{array}$ & $0.264(0.055)^{* * *}$ & $\begin{array}{l}0.433 \\
(0.099)^{* * *}\end{array}$ & $\begin{array}{l}-4.72 \\
(0.174)^{* * *}\end{array}$ & \begin{tabular}{||l}
-3.658 \\
$(0.000)^{* * *}$
\end{tabular} & $\begin{array}{l}-3.007 \\
(0.000)^{* * *}\end{array}$ & $\begin{array}{l}-4.793 \\
(0.000)^{* * *}\end{array}$ & $0.264(0.000)^{* * *}$ & $\begin{array}{l}-1.514 \\
(0.000)^{* * *}\end{array}$ & $\begin{array}{l}-4.715 \\
(0.000)^{* * *}\end{array}$ \\
\hline$\phi$ & \begin{tabular}{|l}
0.906 \\
$(0.045)^{* * *}$
\end{tabular} & $\begin{array}{l}0.882 \\
(0.044)^{* * *}\end{array}$ & $0.956(0.023)^{* * *}$ & $0.840(0.052)^{* * *}$ & $\begin{array}{l}0.815 \\
(0.066)^{* * *}\end{array}$ & $\begin{array}{l}0.970 \\
(0.020)^{* * *}\end{array}$ & $0.928(0.000)^{* * *}$ & $0.898(0.000)^{* * *}$ & $0.956(0.000)^{* * *}$ & $0.840(0.000)^{* * *}$ & $0.840(0.000)^{* * *}$ & $0.970(0.000)^{* * *}$ \\
\hline$\sigma \cdot v$ & $\begin{array}{l}0.177 \\
(0.014)^{* * *}\end{array}$ & $\begin{array}{l}0.303 \\
(0.024)^{* * *}\end{array}$ & $0.200(0.014)^{* * *}$ & $0.126(0.018)^{* * *}$ & $\begin{array}{l}0.319 \\
(0.026)^{* * *}\end{array}$ & $\begin{array}{l}0.223 \\
(0.013)^{* * *}\end{array}$ & $0.028(0.000)^{* * *}$ & $0.022(0.000)^{* * *}$ & $\begin{array}{l}0.022 \\
(0.000)^{* * *}\end{array}$ & $\mid 0.022(0.000)^{* * *}$ & $0.019(0.000)^{* * *}$ & $0.022(0.000)^{* * *}$ \\
\hline$\sigma_{. n}$ & $\begin{array}{l}0.081 \\
(0.021)^{* * *}\end{array}$ & $\begin{array}{l}0.179 \\
(0.036)^{* * *}\end{array}$ & $0.095(0.019)^{* * *}$ & $\mid \begin{array}{l}0.117 \\
(0.022)^{* * *}\end{array}$ & $\begin{array}{l}0.211 \\
(0.039)^{* * *}\end{array}$ & $\begin{array}{l}0.086 \\
(0.017)^{* * *}\end{array}$ & $0.002(0.000)^{* * *}$ & $0.002(0.000)^{* * *}$ & $0.002(0.000)^{* * *}$ & $0.002(0.000)^{* * *}$ & $0.001(0.000)^{* * *}$ & $0.002(0.000)^{* * *}$ \\
\hline $\log -V_{m}$ & & & & & & & $\mid$\begin{tabular}{||l}
-3.087 \\
$(0.000)^{* * *}$
\end{tabular} & $\begin{array}{l}-2.529 \\
(0.000)^{* * *}\end{array}$ & $\begin{array}{l}-3.218 \\
(0.000)^{* * *}\end{array}$ & $\mid \begin{array}{l}-4.143 \\
(0.000)^{* * *}\end{array}$ & $\begin{array}{l}-2.307 \\
(0.000)^{* * *}\end{array}$ & $\begin{array}{l}-3.002 \\
(0.000)^{* * *}\end{array}$ \\
\hline$r_{m}$ & & & & & & & $\mid \begin{array}{l}-4.043 \\
(0.000)^{* * *}\end{array}$ & $\begin{array}{l}-3.436 \\
(0.000)^{* * *}\end{array}$ & $\begin{array}{l}-4.705 \\
(0.000)^{* * *}\end{array}$ & \begin{tabular}{||l}
-4.296 \\
$(0.000)^{* * *}$
\end{tabular} & $\begin{array}{l}-3.045 \\
(0.000)^{* * *}\end{array}$ & $\begin{array}{l}-4.918 \\
(0.000)^{* * *}\end{array}$ \\
\hline $\begin{array}{l}\text { Proportion of signal } \\
\text { explained by } \\
\text { herding: Sigma eta to } \\
\text { SD(log-CSSD-Betas) }\end{array}$ & 0.30862 & 0.38166 & 0.25955 & || 0.46427 & 0.43965 & 0.22470 & $\mid 0.00731$ & 0.00342 & 0.00437 & 0.00637 & 0.00298 & 0.00421 \\
\hline $\begin{array}{l}\text { Log (Maximum) } \\
\text { likelihood values }\end{array}$ & 23.47828 & -95.59491 & -6.44682 & ||49.11612 & -109.2438 & -20.01019 & $\mid-292956$ & -3683678 & -7376260 & $\mid-33092217$ & -7932628 & -3964309 \\
\hline $\begin{array}{l}\text { Schwarz information } \\
\text { criterion }\end{array}$ & -0.12882 & 1.06192 & 0.17044 & $\mid-0.3852$ & 1.1984 & 0.30607 & |29295.76 & 36836.84 & 73762.75 & |330922.3 & 79326.44 & 39643.25 \\
\hline & & & & & & & ficance at & evel. & & & & \\
\hline
\end{tabular}

Panel A in Table 6 exhibits estimation of the State-Space Models (B11), (B21) and (B31) employed in extracting herding towards the Market Portfolio, Book-to-Market and Trading Volume factors, and the proportion of herding explained by each factor. Each model employs the Cross-Sectional Standard Deviations of quantile regression estimated betas at the 5th as well as the 95th quantile. Panel B displays the estimation of the State-Space Models (B12), (B22) and (B32) used in extracting herding towards the Market Portfolio, Book-to-Market and Trading Volume factors, and the proportion of herding explained by each factor employing the Cross-Sectional Standard Deviations of 5 th and 95 th quantile betas. In column $1, \sigma_{. v}$ and $\sigma_{. \eta}$ represent standard deviations of $\nu_{. t}^{s}$ and $\eta_{. t}$, respectively. 
Table 7: Proportion of signal explained by herding based on the Linear Factor Model factor sensitivities.

\begin{tabular}{|l|r|r|r|}
\hline $\begin{array}{c}\text { Beta estimation } \\
\text { method }\end{array}$ & $\begin{array}{c}\text { Market } \\
\text { Portfolio }\end{array}$ & $\begin{array}{c}\text { Book-to- } \\
\text { Market }\end{array}$ & Trading Volume \\
\hline OLS & $25.69 \%$ & $42.22 \%$ & $12.26 \%$ \\
\hline Quantile, $\theta=0.05$ & $30.86 \%$ & $38.17 \%$ & $25.96 \%$ \\
\hline Quantile, $\theta=0.95$ & $46.43 \%$ & $43.97 \%$ & $22.47 \%$ \\
\hline
\end{tabular}

The values reported in Table 7 are extracted from Tables 5 and 6 for easy comparison of values.

5.2.3(a) Herding towards the market portfolio: State-Space Models (B11) and (B12) employing Quantile regression estimated Model $(B)$ betas

Viewing Models (B11) and (B12) in Panels A and B of Table 6 we observe that the parameter $\phi$ of herding variable $H_{m t}$ in both models is significant at the $1 \%$ level of significance. However, Model (B11) is a better fitting than Model (B12) for quantile 0.05 as well as quantile 0.95 . In Model (B11) herding explains $30.86 \%$ of the variation in $\log -\operatorname{CSSD}\left(b_{m t}\right)$ at quantile 0.05 , while $46.43 \%$ at quantile 0.95 . Both these percentages are higher than the $25.69 \%$ of the signal explained by the OLS based better fitting Model (B12) in Table 5. Comparing herd dynamics in Figures $8,11(a)$ and $11(b)$, it follows that there is a lot more persistence in herding as well as incidences of adverse herding towards the market portfolio at quantile 0.95 compared to quantile 0.05 and at the average level. It can be inferred from this pattern that during the high-performance days of stocks, investors are very watchful of the market, quick to respond to the movements in the market and are frequently adjusting their investment strategies to optimize returns on their investments.

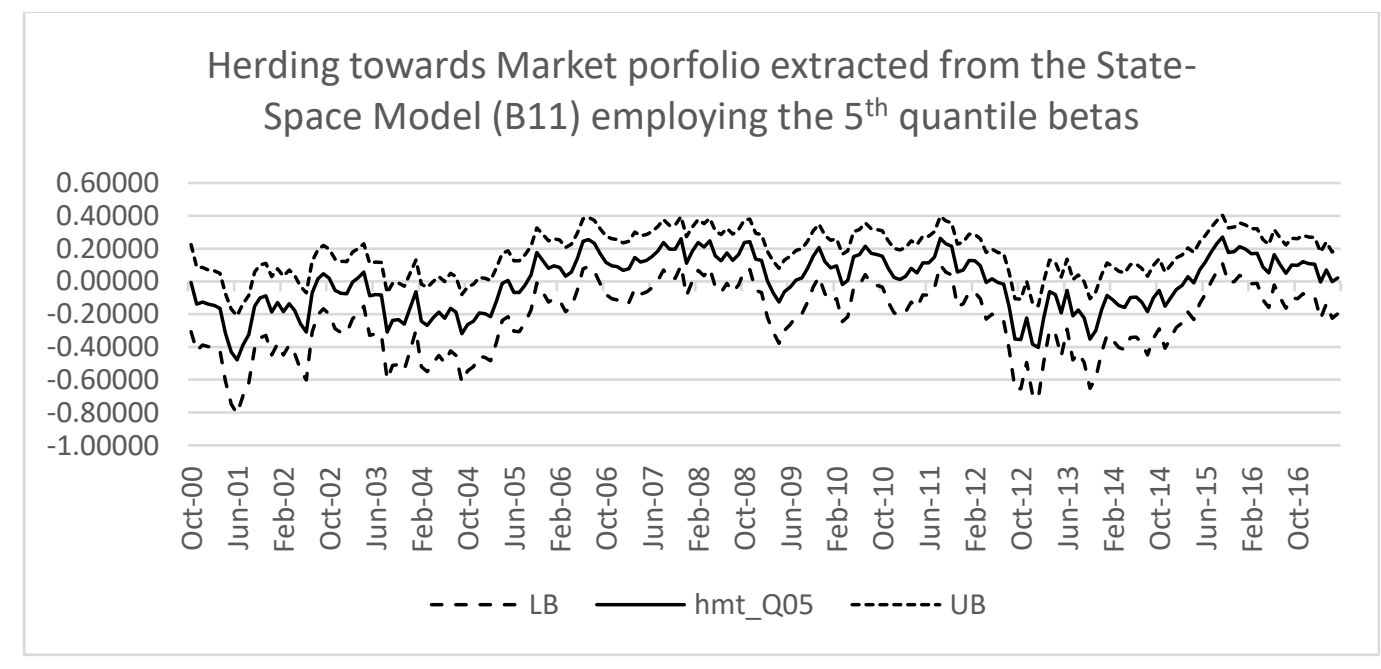


Fig. 11(a): Herd dynamics towards the Market Portfolio based on the $5^{\text {th }}$ quantile betas from the Linear Factor Model used in the State-Space Model (B11); LB and UB are the two standard error lower and upper bounds on $h_{m t}$.

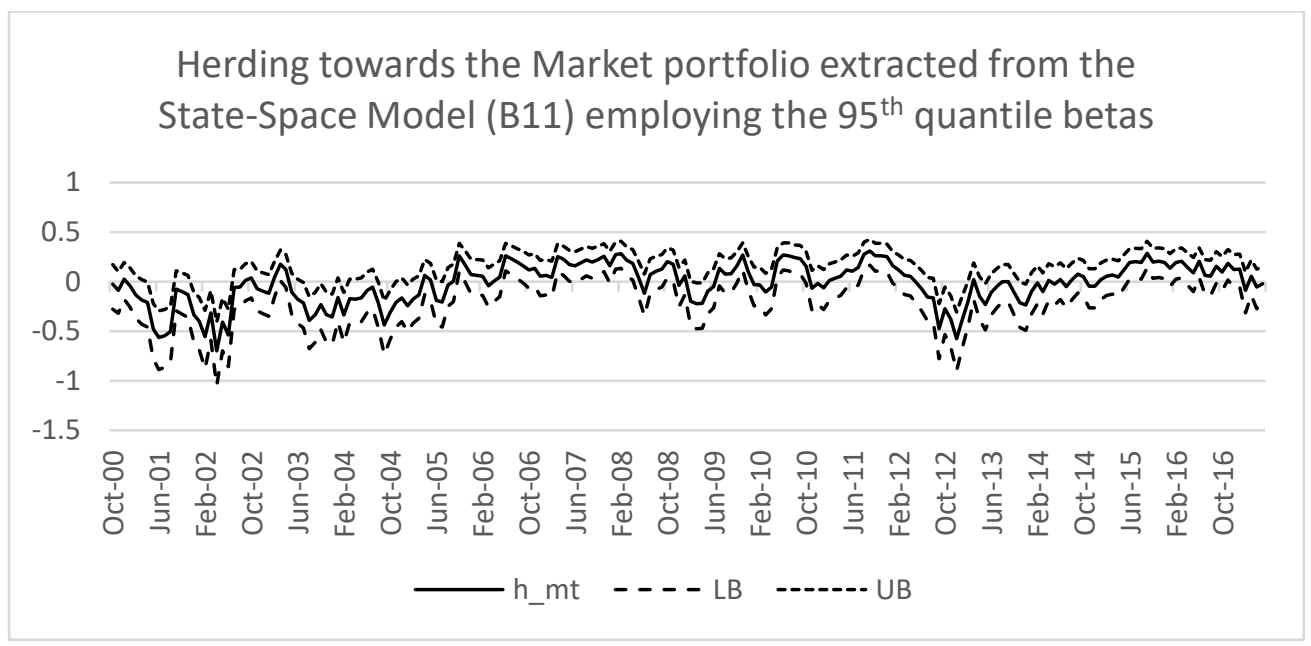

Fig. 11(b). Herd dynamics towards the Market Portfolio based on the $95^{\text {th }}$ quantile betas from the Linear Factor Model used in the State-Space Model (B11); LB and UB are the two standard error lower and upper bounds on $h_{-} m$.

5.2.3(b) Herding towards the Book-to-Market factor: State-Space Models B21 and B22 using Quantile regression estimated Model B betas at quantiles 0.05 and 0.95

As noted earlier, a comparison of Models (B21) and (B22) for quantiles 0.05 and 0.95 in Table 6 reveals that Model (B21) performs better than Model (B22). State-Space Model (B21) shows that herding towards the BM factor explains $38.17 \%$ of the variation in log$\operatorname{CSSD}\left(b_{M T}\right)$ at quantile 0.05 and $43.97 \%$ at quantile 0.95 compared to $42.22 \%$ at the average level (Model (B22) in Table 5). Viewing Figures 9, 12(a) and 12(b), and comparing herding towards BM with herding towards the market portfolio, we observe that BM factor is herded for longer periods compared to market portfolio. The PoSEH towards the BM factor is maximum at quantile 0.95. Comparing POSEH towards BM, market portfolio and trading volume, we find that $\mathrm{BM}$ is herded more frequently compared to other factors. Referring to the assertion in Footnote 2 from Dempsey (2010) that 'the BM variable absorbs market movements as a proxy for financial risk', it can be inferred that the BM factor herding suggests a risk-aversion tendency of investors in the Australian market. While there are incidences of adverse herding during 2000-2001 and around 2013 based on CSSDs of quantile 0.05 betas, the incidences of adverse herding based on CSSDs of quantile 0.95 betas are more frequent and intense and include the GFC period along with many other 
periods. There is no significant adverse herding during the short-selling ban period; the movements are generally sideways and reflect the effectiveness of the regulation.

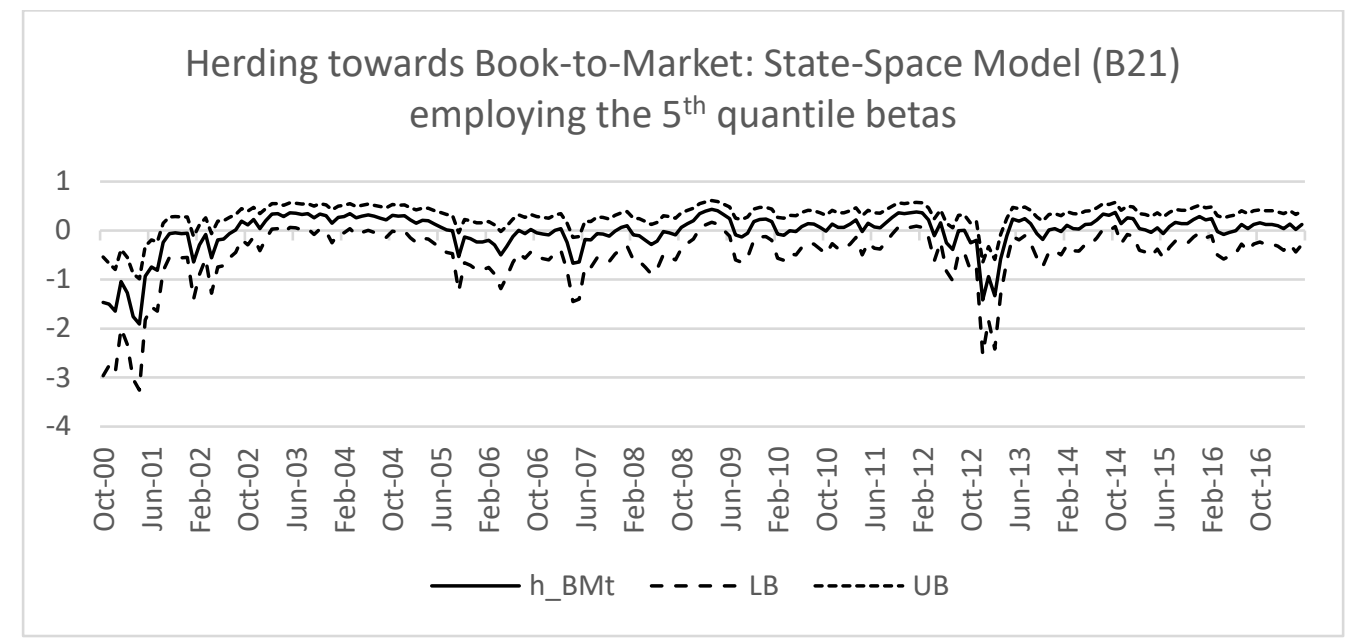

Fig. 12(a). Herd dynamics towards Book-to-Market factor based on the $5^{\text {th }}$ quantile betas from the Linear Factor Model used in the State-Space Model (B21); LB and UB are the two standard error lower and upper bounds on $h_{-} B M t$.

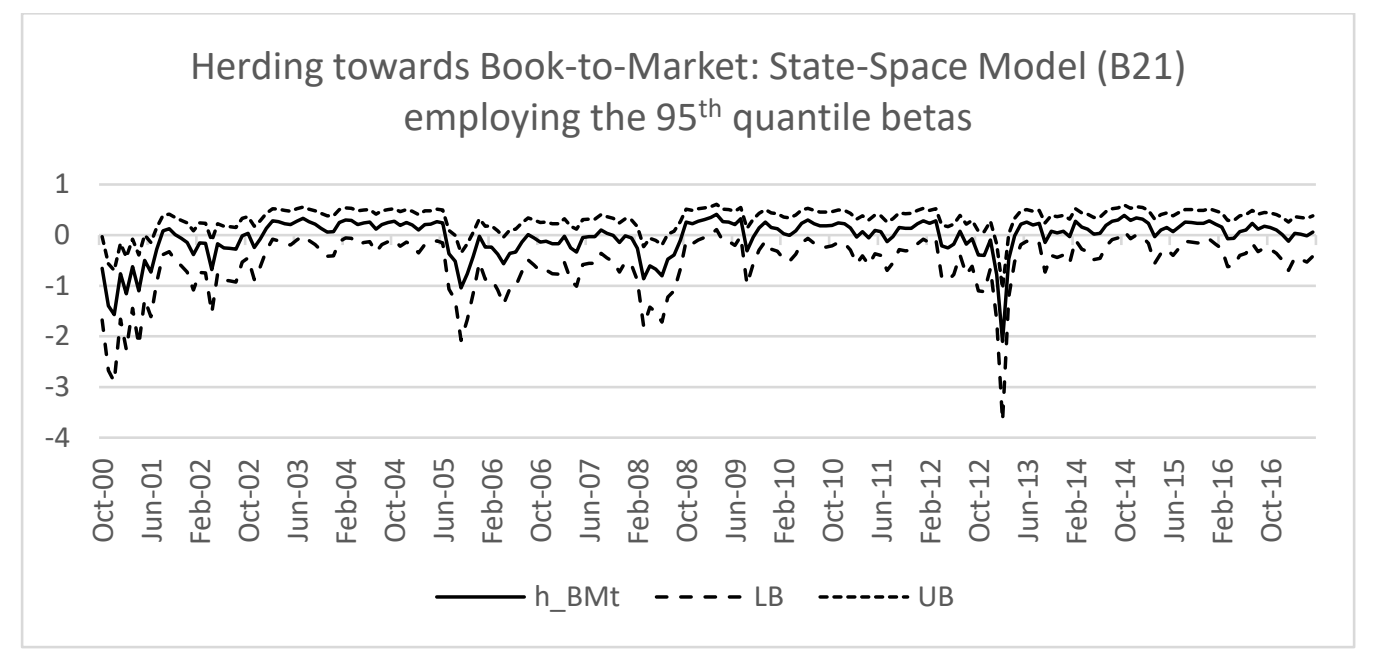

Fig. 12(b). Herd dynamics towards Book-to-Market factor based on the $95^{\text {th }}$ quantile betas from the Linear Factor Model used in the State-Space Model (B21); LB and UB are the two standard error lower and upper bounds on $h_{-}$BMt.

5.2.3(c) Herding towards the Trading volume factor: State-Space Models (B31) and (B32) using Quantile regression estimated Model (B) betas at quantiles 0.05 and 0.95

We observe in Table 6 that State-Space Model (B31) performs better than Model (B32) for extracting herding towards the trading volume using quantiles 0.05 and 0.95 betas. Herding towards the trading volume explains $25.96 \%$ of the variation in $\log -\operatorname{CSSD}\left(b_{T R t}\right)$ at quantile 0.05 and $22.47 \%$ at quantile 0.95 compared to $12.26 \%$ at the average level (Table 7 ). 
Comparing time dynamics of herding towards trading volume in Figures 10 (a), 10 (b), 13 (a) and $13(b)$, it follows that there is no significant herding towards TR on an average day, but investors do observe closely the movements of trading volume on the low as well as on the high-performance days of stock returns. These findings on trading volume tie closely with the findings of Gebka and Wohar (2013). Based on OLS estimation they report that there is no causal link between trading volume and return; the volume-return causality is nonpersistent in nature and is of limited use for return forecasting, and therefore, there is support for the efficient market hypothesis. However, their results show volume-return causality in quantiles. Inspecting Figures 13(a) and 13(b), we observe low levels of herding/adverse-herding towards trading volume during calmer/turbulent periods. Thus, it can be concluded that herding towards the trading volume may be endorsing the presence of information rich investors as argued by Stickel and Verrecchia (1994), who would be savvy enough to be risk-averse during the calmer as well as the turbulent periods.

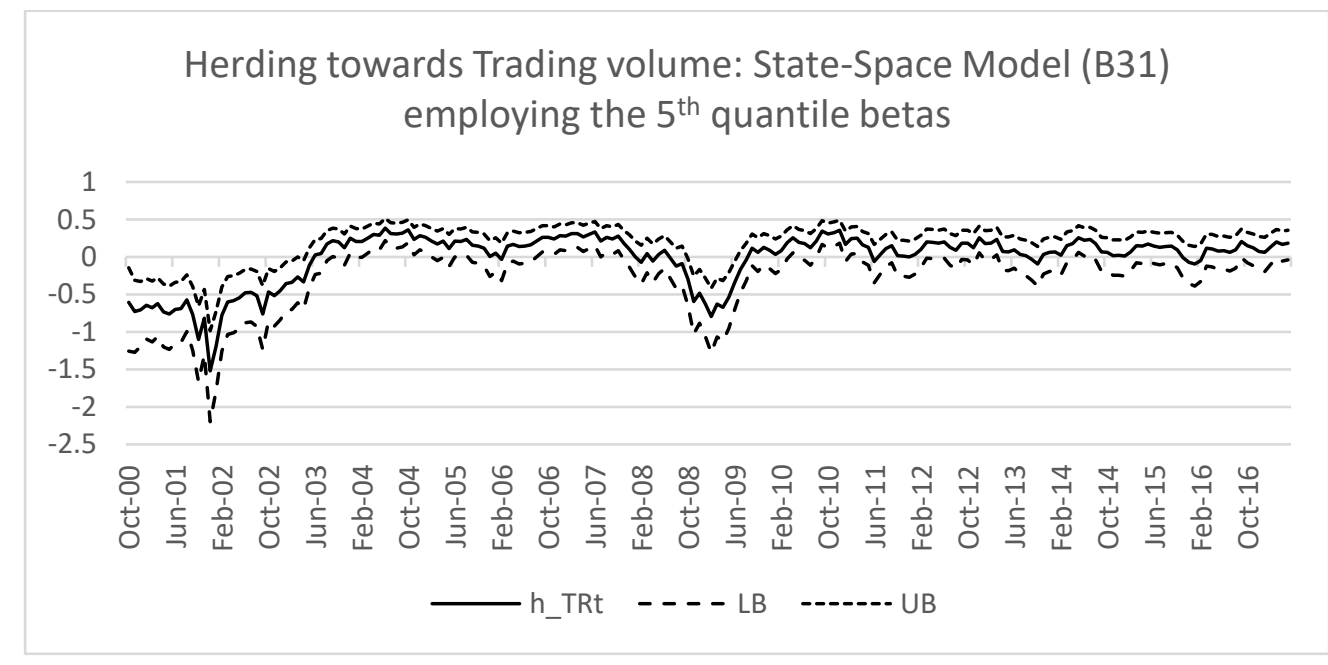

Fig. 13(a). Herd dynamics towards Trading volume based on the $5^{\text {th }}$ quantile betas from the Linear Factor Model used in the State-Space Model (B31); LB and UB are the two standard error lower and upper bounds on h_tRt. 


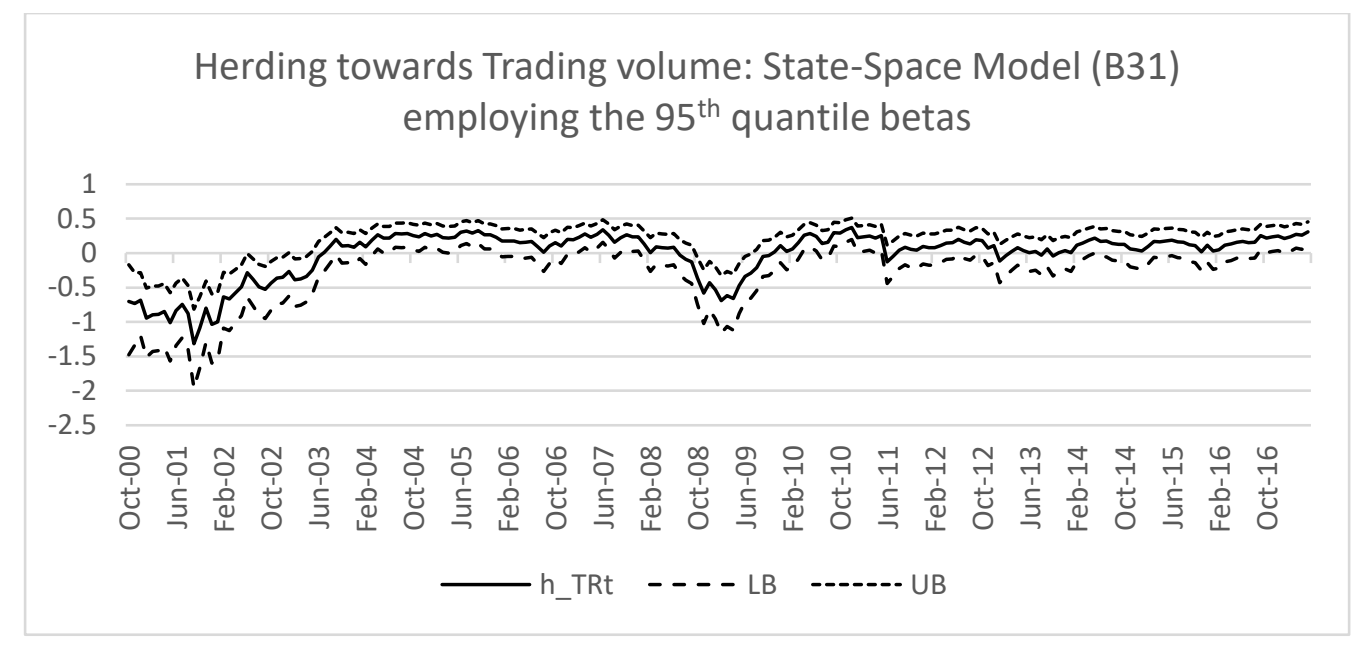

Fig. 13(b). Herd dynamics towards Trading volume based on the $95^{\text {th }}$ quantile betas from the Linear Factor Model used in the State-Space Model (B31); LB and UB are the two standard error lower and upper bounds on h_TRt.

\section{Conclusion}

This paper examines investor-herding and risk-profiles link for understanding the implied risk in a stock market that carries implications for portfolio diversification and asset pricing. Employing Australian data, we use an in-depth time series approach to evaluate herd dynamics towards the market portfolio, Book-to-Market ratio and trading volume factors and to find the proportion of signal explained by herding (POSEH) in each case. Specifically, State-Space models are used for extracting the latent herding component from the crosssectional standard deviations (CSSD) of factor sensitivities estimated using the quantile regression and the OLS methods that allow capturing the effect of various factors at the extreme quantiles and at the average level of the return distribution.

We observe many periods of herding and adverse herding towards the market portfolio; the intensity of both events is much greater when extreme quantile betas are employed compared to the use of average betas. The POSEH using the OLS and the $5^{\text {th }}$ and $95^{\text {th }}$ quantile betas are $34.08 \%, 22.43 \%$ and $43.05 \%$ (Table 2), respectively, suggesting that the level of herding is not homogenous across the return distribution; investors value their assets differently on the low- and the high-performance days of stock returns compared to an average day. We observe investors herd during calmer periods and show adverse herding behaviour - a sign of risk aversion, during turbulent periods. The existence of herding and adverse herding at the extreme quantiles suggests that such behaviour can emerge during 
the worst and the best performance days of stock returns and that risk aversion plays an important part in herd behaviour.

Market volatility has a significant negative relationship with CSSD of market betas of securities at all levels of the return distribution and a strong negative effect on herding. The PoSEH drops when market volatility is used as an explanatory variable in the State Space models. It has the most effect on high-performance days of stock returns, has a moderate effect on an average day and virtually no effect on low-performance days (Table 2).

The POSEH based on the linear factor model shows that herding towards the market portfolio (trading volume) is stronger during the best (the worst) performance days of stock returns. However, POSEH towards the BM factor is high at all levels of the return distribution suggesting BM as the most desired herding factor. Keeping in view the assertion 'the BM variable absorbs market movements as a proxy for financial risk' from Dempsey (2010), it can be inferred that the BM factor herding in the Australian market endorses investors' riskaversion tendencies. There are incidences of adverse herding towards this factor during 2000-2001, GFC and around 2012-2013 (the Greek Govt. debt crisis period), but no such effect during the short-selling ban period (Nov 2008-May 2009). The non-significant sideways herding movements during the short-selling ban period imply the presence of a regulated stock market environment. The dominance of BM factor herding among others, and the occurrence of herding/adverse-herding during calmer/turbulent periods when the investor confidence is high/low supports the risk-aversion tendencies of investors.

\section{References}

Arnott, R.D., Hsu, J., Moore, P., 2005. Fundamental indexation. Financial Analysts Journal. 61, 83-99.

Asch, E., 1952. Social Psychology, Englewood Cliffs, N. J., Prentice Hall.

Bai, Y., Chang, E.C., Wang, J., 2006. Asset prices under short-sale constraints. Working paper, 'web.mit.edu/wangj/www/pap/BCW_061112.pdf'.

Barnes, M., Hughes, A., 2002. A quantile regression analysis of the cross section of stock market returns. Federal Reserve Bank of Boston working paper. 02-2002, 1-34. 
Bohl, M.T., Klein, A.C., Siklos, P.L., 2013. Short-selling bans and institutional investor's herding behaviour: Evidence from the Global Financial Crisis, CIGI Papers, No. 18, https://www.cigionline.org.

Buchinsky, M., 1997. The dynamics of changes in the female wage distribution in the USA: A quantile regression approach. Journal of Applied Econometrics. 13, 1-30.

Buchinsky, M., 1998. Recent advances in quantile regression models: A practical guideline for empirical research. Journal of Human Resources. 33, 88-126.

Chang, E.C., Cheng, J.W., Khorana, A., 2000. An examination of herd behaviour in equity markets: An international perspective. Journal of Banking and Finance. 24, 1651-1679.

Chiang, T.C., Li J., Tan, L., 2010. Empirical investigation of herding behaviour in Chinese stock markets: Evidence from quantile regression analysis. Global Finance Journal. 21, 111-124.

Chiang, T.C., Zheng, D., 2010. An empirical analysis of herd behaviour in global stock markets. Journal of Banking \& Finance. 34, 1911-1921.

Christie, W.G., Huang, R.D., 1995. Following the Pied Piper: Do individual Returns Herd around the Market? Financial Analyst Journal. 51, 31-37.

Demirer, R., Kutan, A., Chen, C., 2010. Do investors herd in emerging markets? Evidence from the Taiwanese market. Journal of Economic Behaviour \& Organization. 76, 283-295. Dempsey, M., 2010. The book-to-market equity ratio as a proxy for risk: evidence from Australian market. Australian Journal of Management. 35, 7-21.

Duan, X., Guo, L., Li, F. W., Tu, J., 2019. Sentiment, Limited Attention and Mispricing. European Financial Management Association Conference-2019, University of Azores, S. Maguel, Portugal.

Economou, F., Kostakis, A., Philippas, N., 2011. Cross-country effects in herding behaviour: Evidence from four South European markets. Journal of International Financial Markets, Institutions \& Money. 21, 443-460.

Effinger, M.R., Polborn, M.K., 2001. Herding and anti-herding: A model of reputational differentiation. European Economic Review. 45, 3, 385-403. 
Engle, R. F., Manganelli, S., 2004. CAViaR: Conditional Value at Risk by Regression Quantile. Journal of Business, Economics and Statistics. 22, 367-381.

Fama, E. F., French, K. R., 1992. The cross-section of expected stock returns. Journal of Finance. 47, 427-465.

Fama, E. F., French, K. R., 2012. Size, value and momentum in international stock returns. Journal of Financial Economics. 105, 457-472.

Fama, E., MacBeth, J., 1973. Risk, return and equilibrium: Empirical tests. Journal of Political Economy. 81, 607-636.

Ferson, W.E., Harvey, C.R., 1991. The variation of economic risk premiums. Journal of Political Economy. 99, 285-315.

Ferson, W.E., Harvey, C.R., 1993. The risk and predictability of international equity returns. Review of Financial Studies. 6, 527-566.

Gebka, B., Wohar, M.E., 2013. Causality between trading volume and returns: Evidence from quantile regressions. International Review of Economics and Finance. 27, 144-159.

Grinblatt, M., Titman, S., Wermers, R., 1995. Momentum investment strategies, portfolio performance, and herding: A study of mutual fund behaviour. American Economics Review. 85(5), 1088-1105.

Hwang, S., Salmon, M., 2004. Market stress and herding. Journal of Empirical Finance. 11, 585-616.

Henker, J., Henker, T., Mitsios, A., 2006. Do Investors herd intraday in Australian equities? International Journal of Managerial Finance. 2 (3), 196-219.

Koenker, R., Bassett, G., 1978. Regression quantiles. Econometrica. 46, 33-50.

Koenker, R., Hallock, K., 2001. Quantile regression. Journal of Economics Perspectives. 15, 143-56.

Lao, P., H. Singh, 2011. Herding behaviour in the Chinese and Indian stocks market. Journal of Asian Economics. 22, 495-506.

Lakonishok, J., Shleifer, A., Vishny, R.W., 1992. The impact of Institutional Trading on stock prices. Journal of Financila Economics. 32, 23-44. 
Nath, H.B., Brooks, R.D., 2015. Assessing the idiosyncratic risk and stock returns relation in heteroskedasticity corrected predictive models using quantile regression. International Review of Economics and Finance. 38, 94-111.

Peterkort, R.F., Nielson, J.F., 2005. Is the book-to-market ratio a measure of risk? Journal of Financial Research. 28, 487-502.

Prechter, R.R. Jr., 2001. Unconscious herding behaviour as the Psychological Basis of Financial market trends and patterns. The Journal of Psychology and Financial Markets. 2(3), 120-125.

Scharfstein, D.S., Stein, J. C., 1990. Herd behaviour and investment. The American Economic Review, Nashville. 80, $465-479$.

Stickel, S.E., Verrecchia, R.E., 1994. Evidence that trading volume sustains stock price changes. Financial Analysts Journal. 50, 57-67.

Yao, J., Ma, C., He, W.P., 2014. Investor herding behaviour of Chinese stock market. International Review of Economics and Finance. 29, pp12-29. 